\title{
Marine Macroalgae, a Source of Natural Inhibitors of Fungal Phytopathogens
}

 \\ 1 MARE-Marine and Environmental Sciences Centre, ESTM, Politécnico de Leiria, 2520-641 Peniche, Portugal; \\ rafael.felix@ipleiria.pt \\ 2 REQUIMTE/LAQV, Laboratório de Farmacognosia, Faculdade de Farmácia, Universidade do Porto, \\ 4050-313 Porto, Portugal; valentao@ff.up.pt \\ * Correspondence: tania.vicente@ipleiria.pt (T.F.L.V.); marco.lemos@ipleiria.pt (M.F.L.L.); \\ carina.r.felix@ipleiria.pt (C.F.)
}

check for updates

Citation: Vicente, T.F.L.; Lemos, M.F.L.; Félix, R.; Valentão, P.; Félix, C. Marine Macroalgae, a Source of Natural Inhibitors of Fungal Phytopathogens. J. Fungi 2021, 7, 1006. https://doi.org/10.3390/jof7121006

Academic Editor: Samantha

C. Karunarathna

Received: 16 October 2021

Accepted: 23 November 2021

Published: 25 November 2021

Publisher's Note: MDPI stays neutral with regard to jurisdictional claims in published maps and institutional affiliations.

Copyright: (c) 2021 by the authors. Licensee MDPI, Basel, Switzerland. This article is an open access article distributed under the terms and conditions of the Creative Commons Attribution (CC BY) license (https:// creativecommons.org/licenses/by/ $4.0 /)$.

\begin{abstract}
Fungal phytopathogens are a growing problem all over the world; their propagation causes significant crop losses, affecting the quality of fruits and vegetables, diminishing the availability of food, leading to the loss of billions of euros every year. To control fungal diseases, the use of synthetic chemical fungicides is widely applied; these substances are, however, environmentally damaging. Marine algae, one of the richest marine sources of compounds possessing a wide range of bioactivities, present an eco-friendly alternative in the search for diverse compounds with industrial applications. The synthesis of such bioactive compounds has been recognized as part of microalgal responsiveness to stress conditions, resulting in the production of polyphenols, polysaccharides, lipophilic compounds, and terpenoids, including halogenated compounds, already described as antimicrobial agents. Furthermore, many studies, in vitro or in planta, have demonstrated the inhibitory activity of these compounds with respect to fungal phytopathogens. This review aims to gather the maximum of information addressing macroalgae extracts with potential inhibition against fungal phytopathogens, including the best inhibitory results, while presenting some already reported mechanisms of action.
\end{abstract}

Keywords: algae phenols; antifungal activity; bioactive compounds; brown algae; crop losses; fungal membrane disruption; fungal resistance; lipophilic compounds; macroalgae metabolites; plant pathogens

\section{Introduction}

Plant pests pose a paramount problem that has been increasing in recent years. The exact production losses due to these phytopathogens are hard to quantify but it is estimated that plant pests account for $20-40 \%$ of annual crop production losses [1,2], at a cost of more than 185 billion euros [3]. Included among these pests, fungal pathogens are one of the most damaging agents in plants, accounting for the devastation of myriad fruits and crops, which results in vast economic losses [4], and ultimately reduces food availability for a continuously increasing world population [5,6]. In fact, diseases provoked by fungi or related microorganisms have already caused starvation scenarios, such as the Irish Potato Famine in the 19th century, caused by a fungal-like oomycete, which led to a million of deaths, mass emigration, and economical and political crisis in Ireland $[7,8]$. Phytopathogenic fungi were also responsible for the baring of landscapes caused by Dutch elm blight and chestnut blight [8] and the complete ruin of 30\% of world food crops in 2012 [3]. Currently, it is predicted that phytopathogenic fungi are responsible for about $80 \%$ of plant diseases [9-11], for which the absence of control can lead to disastrous global crop losses [6,12]. Even the remaining crops, potentially infected but without symptoms, can raise concerns about consumption safety [13]. Moreover, current and forecasted climatic change scenarios, leading to the increase of temperature and humidity, are crucial 
conditions promoting the dispersion and development of phytopathogenic fungi, giving cause for extra concerns [12,14].

The regular application of agrochemicals with antimicrobial properties is the most effective method against these microbial phytopathogens, but it is expensive and environmentally harmful, prevailing in the ecosystem and damaging it $[15,16]$. Every year, farmers spend more than 6 billion euros on such products to control the microbial infections, which represents a quarter of the costs for agricultural purposes [17]. For sustainability reasons, novel alternative methods have been sought that will have the same effectiveness, improve agricultural techniques, and enhance food production, ensuring the quality and security of food [18]. Several techniques and methodologies have been tested to minimize plant and financial losses either by directly targeting the microbial phytopathogens or by preventive measures, conferring resistance to the plant hosts. The laboratory manipulation of synthetic compounds to increase the effectiveness of products [19] or the introduction of "site-specific fungicides" [20] to control the most problematic and common microbial pathogens, have been suggested. Nevertheless, these products remain inefficient due to the great genetic resources and adaptative abilities of phytopathogens, which allow them to acquire resistance and overcome the efficiency of these types of products [20,21]. The biocontrol technique, characterized by the introduction of an antagonist microbial organism, harmless to the host but damaging for the phytopathogen [14], has been tested in vitro [2,22-26] and shown a great potential in field applications [2]. This methodology is characterized by the absence of chemicals, providing a viable and sustainable agriculture [27]. Although some limitations associated with the establishment and maintenance of biocontrol agents have been identified [2], including their interaction with the plant microbial community [28], the continuous stress conditions provoked in the host plant, the inconsistent results among tests $[14,29,30]$, and the poor effectiveness compared to chemical fungicides, are factors which could and should be improved [29-31]. Though their potential can be enhanced through their combination with chemical interventions [28,32], this fails to solve the harm these compounds pose to the environment. The exploitation of genetic manipulation to alter the plant host genome with the insertion of resistance genes [33] was quickly shown to be ineffective against non-target phytopathogenic microorganisms and/or the emergence of new microbial races [15]. Therefore, the continuous search for biodegradable natural compounds, eco-friendly and effective against phytopathogenic microorganisms, is paramount [34], promising as it does to enhance food production and ensure the quality and security of agricultural products [18].

Marine habitats have been increasingly investigated due to the potential of bioactive products synthesized by the micro- and macro-organisms inhabiting them [35] being used in medicine and industry [36]. Seaweeds are one of the most attractive sources of bioactive substances due to their unique and diversified production of phenolic compounds, polysaccharides, fatty acids, and pigments. It is known that macroalgal applications have the potential to go beyond the ongoing uses in cosmetics, agricultural fertilizers, and the food industry [37]. Marine algae have revealed interesting compounds with antibiotic activity against pathogenic bacteria and fungi. Polysaccharides, polyphenols, carotenoids, proteins, peptides, sterols, terpenes, and fatty acids, among others, are the main constituents of algae that are associated with the antimicrobial properties of seaweed extracts [38-40]. Moreover, some of these algae compounds are capable of stimulating the natural defences of plants and promoting their resistance against microbial attacks, exhibiting a priming potential $[39,41]$.

Considering the problems referred to above and the constant reduction of the effectiveness of available eco-friendly methodologies, given the promising results of in vitro assays, macroalgae constitute a source of diverse and natural compounds with antimicrobial potential against phytopathogenic fungi. Given this framework, the present review focuses on the potential of macroalgae-derived products, aiming to combine the available information regarding the potential/activity of fungal phytopathogen inhibition, while 
trying to clarify /link some "compound mode-of-action" and provide help and insights for future research into antimicrobial products derived from seaweeds.

\section{Materials and Methods}

For the present literature revision, a search was performed in the SCOPUS database to retrieve the maximum amount of information about the antimicrobial potential and activity of macroalgae available up until 25 February 2021. The following word combinations were used: (Antifung* OR fungicid*) AND (Plant* OR crop* OR agricultur* OR veget* OR phytopatho*) AND (Macroalga* OR seaweed). The search returned 126 documents.

\section{Macroalgae Potential in the Eradication of Fungal Infections in Plants}

\subsection{Phytopathogenic Fungi}

Fungal phytopathogens represent a significant threat for plant species [9,42], colonizing a wide range of diversified host plants. Their infections are particularly worrisome in crops for human consumption [42] because they can limit the availability of food to satisfy human nutritional needs. Strange and Scott already highlighted this problem in their review of 2005 [6] describing all the fungal pathogens and respective diseases from the main crop plants used for consumption. Specifically, fungi exhibited a devastating effect on cereal crops (maize, wheat, soybean, barley, millet, and rice), fruits (including a vast range of plant species), roots, tubers (yam, potato, and sweet potato), and vegetables [6,42]. The damages caused to a given plant depend upon the fungal feeding requirement [10]. The biotrophic fungi completely rely on their living host to survive and to grow [43]. Nevertheless, the fast reproduction of the fungi leads to a propagation not sustained by the plant, resulting in deformations of the host shape in various organs and the ripping of superficial tissues, leaving the plant susceptible to other pathogens and diseases. Necrotrophic fungi colonize the dead plant host, and their attack can also happen in various organs [44], affecting the superficial tissues of roots and trunk, as well as the inner vessels of the plants [14]. Hemibiotrophs are fungi that require the host to be alive, and, later on, they need dead matter to complete their life cycle. The damage caused by this type of fungi is local and specific $[43,45]$. Several researchers have been trying to compile information about phytopathogenic fungi, including the generation of databases analysing the molecular interactions between host and pathogen, such as the "One Stop Shop Fungi" [46] and projects aiming at the collection of phytopathogenic genera reported in the literature [47-49], as well as the "Genera of phytopathogenic fungi: GOPHY" project developed in 2017. This project has already described hundreds of species distributed across 62 genera. Table 1 presents some of the most relevant phytopathogenic fungal genera, as well as their respective targets (host plants).

These phytopathogenic microorganisms are an old and recurrent problem that has been extensively studied to find effective solutions to control their worldwide propagation. A promising alternative based on natural compounds of macroalgae (direct use of dry powder or extracts) has been explored since the last century, testing the antifungal potential of metabolites through in vitro methodologies (e.g., mycelial and spore germination inhibition) and in vivo assays (e.g., validation in plants). The antifungal potential of extracts obtained from macroalgae is highly influenced by the methodology and solvents used to obtain them, which promote the extraction of different types of compounds with different bioactivities. Several researchers highlight the use of organic solvents as the most promising way to obtain extracts with antifungal activity in macroalgae [50,51], which can be ascribed to their high affinity for phenolic and lipidic compounds, both of which are associated with good inhibitory activity against fungi [52]. The most reported mechanism for this antifungal activity is the disruption of the fungal membrane caused by bioactive algae extracts [53], which disturbs the electron transport chain, increasing membrane fluidity and causing conformational disorders that are expressed by the outflow of important cytoplasmatic components [54,55], resulting in fungal cell death [56]. 
Table 1. Relevant phytopathogenic fungi genera and their hosts.

\begin{tabular}{clc}
\hline Fungal Genera & \multicolumn{1}{c}{ Host Plant } & References \\
\hline Alternaria & $\begin{array}{l}\text { Fruit plants, such as tomato (Lycopersicon esculentum) } \\
\text { and apple (Malus domestica) }\end{array}$ & {$[49,57-59]$} \\
\hline Aspergillus & Seeds, nuts, and fruits of a wide range of plant species & {$[57,58,60-62]$} \\
\hline Botrytis & Wide range of plant hosts & {$[57,63,64]$} \\
\hline Colletotrichum & $\begin{array}{l}\text { Mediterranean plants and trees (fruits), tropical } \\
\text { species and vegetables }\end{array}$ & {$[42,47,65-69]$} \\
\hline \multirow{2}{*}{ Fusarium } & $\begin{array}{l}\text { The broad range of hosts include mono- and } \\
\text { dicotyledons in greenhouses, cereals crops, and other } \\
\text { plant species, such as tomato, upland cotton } \\
\text { (Gossypium hirsutum), banana (Musa sp.), and plants } \\
\text { belonging to the Brassicaceae family }\end{array}$ & {$[42,52,57,63,64,70-75]$} \\
\hline Penicillium & $\begin{array}{l}\text { Fruits and vegetables } \\
\text { Puccinia }\end{array}$ & Wheat crops (Triticum aestivum) \\
\hline & $\begin{array}{l}\text { Root pathogen of a wide range of hosts, including } \\
\text { tomato, soybean (Glycine max), pepper (Capsicum } \\
\text { annuum), eggplant (Solanum melongena), watermelon } \\
\text { (Citrullus lanatus), upland cotton, sunflower } \\
\text { (Helianthus annuus), rice (Oryza sativa), and potato } \\
\text { (Solanum tuberosum) }\end{array}$ & {$[57,58,76,77]$} \\
\hline Rhizoctonia & {$[42,47,64,78]$} \\
\hline Rhizopus & Brassicaceae plants & \\
\hline
\end{tabular}

\subsection{Macroalgae Potential against Phytopathogenic Fungi}

\subsubsection{In Vitro Antifungal Potential}

The potential of activities presented by the metabolites produced by seaweed is influenced by a myriad of combined environmental [81,82] and biological [83-85] factors of the algae species involved, in addition to the methodology adopted for the recovery of the diverse bioactive compounds [85-91]. The antifungal potential/activity of the macroalgae follows the same pattern.

An overwhelming majority of studies reporting antifungal activity/potential come from brown algae, followed by the green and red algae (extensively reported in the Supplementary Material; Tables S1-S12). Additionally, there are studies demonstrating an exclusive antifungal activity from brown macroalgae against fungi species (Table 2). Botrytis cinerea [63], Cladosporium herbarum [56], Geotrichum sp. [63], Phialophora cinerescens, Phoma tracheiphila [65], Sclerotinia sclerotiorum, Sclerotium rolfsii [92], and Verticillium dahliae [63,93] are some examples of fungi that only presented susceptibility to algae extracts belonging to the class Phaeophyceae. Exceptions were found in the species Colletotrichum gloeosporioides, Pseudocercospora fijiensis [94], and Pyricularia oryzae [95], which were only inhibited by red algae, a group also possessing a large amount of diverse relevant compounds [96]. The genus Alternaria is one of the most prevalent phytopathogenic groups, responsible for soft-rotting infections and Alternaria blight in apple trees and tomato plants, respectively, leading to important fruit losses $[58,97]$. In addition to this genus, Penicillium expansum and Aspergillus niger are also soft-rotting devastating fungi for a large range of fruits and vegetables. In a work performed by Vehapi, the in vitro antifungal potential of a green alga, Ulva lactuca, was demonstrated, suggesting the presence of polyphenols responsible for the oxidation of important elements present in Alternaria alternata and P. expansum [58].

Colletotrichum is one of the most devastating genera of phytopathogenic fungi, due to its cross-infection capacity affecting a large range of hosts, including fruit trees (tropical and Mediterranean species), vegetables, and one of the most economically important plants, sugarcane $[42,47,65-69]$. The enormous losses caused in strawberry cultures are noticeable [98]. Moreau and colleagues reported significant inhibitory activity exhibited 
by hexane extracts of brown algae, Dictyota dichotoma and Dilophus spiralis, against Colletotrichum acutatum [65]. This species can damage the fruit (black spot) and root (necrosis and crown rot) of strawberry, pepper, eggplant, tomato, and beans. Additionally, Colletotrichum falcatum, a causative agent of red rot in sugarcane, is responsible for losses of hundreds of million dollars every year [99,100]. Ambika and Sujatha [66] tested the susceptibility of this fungus to the aqueous and ethanolic extracts of Sargassum myricocystum, Gracilaria edulis, and Caulerpa racemosa, and observed higher antifungal activity in brown algae, corroborating their higher potential. The ethanolic solvent used promoted the extraction of lipophilic compounds from macroalgae that are known for their antifungal activity. Also present in brown algae is a subgroup of phenolic compounds, the flavonoids, possessing a wide range of bioactivities, antifungal activity among them [66]. Rhodophyta algae also exhibited antifungal activity against the agents responsible for anthracnose, Colletotrichum species, in tropical crops [67] and Capsicum annuum plants [69]. The high inhibition of red algae observed against C. gloeosporioides and Colletotrichum musae can be related to the natural compounds produced by algae as a defence mechanism against microbial attack $[101,102]$. The sessile characteristic of the algae leads to the production of phenols [103] and terpenes (di-, sesquiterpenes) [102], including halogenated monoterpenes, [101] to self-protect under stress conditions [68], and other compounds, such as fatty acids [104], to which can be attributed antifungal activity against phytopathogenic fungi [102]. Moreover, Mani and Nagarathnam demonstrated the capacity of k-carrageenan, a polysaccharide produced by the Rhodophyta group, to alter the membrane permeability of C. gloeosporioides, an antifungal mechanism that can suppress their development [69].

The genus Fusarium is the most devastating soil-borne agent for several crops, and is known to produce toxins that are prejudicial for animals and in plants to be responsible for fusarium wilting, snow mold, the whitening of ears in crops, and root rot diseases [52,57]. Although the majority of studies focus on the evaluation of algae extracts as antifungal agents against two persistent phytopathogenic species, Fusarium oxysporum and Fusarium solani (Table 2), which are involved in vascular bundle wilt with incidence in various economically relevant plants, such as eggplant, watermelon [72], pigeon pea [105], sunflower, and tomato [75], there are also a high number of studies reporting the potential of algae extracts tested against a wide range of other Fusarium species $[51,57,63,96]$.

Diverse macroalgae species belonging to red, green, and brown macroalgae have been investigated for their antifungal potential against Fusarium species, and their potential has been observed in in vitro assays, as well as in field and in greenhouse conditions [71]. Rizvi and Shameel reported a higher susceptibility to methanolic extracts produced by Chlorophyta, Phaeophyta, and Rhodophyta in F. solani, while F. moniliforme was only inhibited by methanolic extracts from brown and red alga, Dictyota hauckiana and Botryocladia leptopoda, respectively, showing a different interaction between extracts and fungal species [96]. In another work, Tyśkiewicz and colleagues presented the antifungal activity of an aqueous extract, obtained by supercritical carbon dioxide extraction from Fucus vesiculosus, as a potential antifungal agent and/or fungistatic due to the complete degradation of macroconidia of F. oxysporum and F. culmorum [57] observed in in vitro tests. Such results are extremely important since these globally spread species are very persistent in soil, making their elimination much more challenging.

Malini [51] tested different promising organic solvents to extract bioactive compounds possessing antimicrobial activity. Their antifungal potential was confirmed, and all the organic extracts of Anthophycus longifolius (then identified as Sargassum longifolium) were able to inhibit the growth of Fusarium sp., chloroform highlighted as the most effective solvent [51]. A diversified range of different compounds was identified in this extract, namely proteins, phenolic compounds, alkaloids, coumarin, and sugars [51]. Some of these compounds, such as phenolic compounds, in addition to terpenoids, a class of organic compounds usually abundant in brown algae, are commonly reported to possess antifungal activity [63] against phytopathogenic fungi belonging to the Fusarium genus [106]. Additionally, the high antifungal activity of the chloroform extract of Hormo- 
physa cuneiformis and the methanolic extract of Polycladia myrica (then named as Cystoseira myrica) and Sargassum cinereum against Fusarium spp. have been associated with their richness in fatty acids, including saturated (lauric acid, palmitic, myristic, and stearic), monounsaturated, and polyunsaturated fatty acids (arachidonic, dihomo- $\gamma$-linolenic, and cis-11,14-eicosadienoic) [56], as well as to the presence of essential oils with antimicrobial activities already described [107]. Specifically, some of these acid compounds were tested against Fusarium spp., and lauric, myristic, and palmitic acids demonstrated moderate inhibitory activity [108]. In the study of Ambreen et al. [109], the presence of polyunsaturated esters was found to be responsible for the antifungal activity of an ethanolic extract of Sargassum ilicifolium against F. oxysporum by disrupting its membrane.

In parallel with the Fusarium genus, several studies have been developed to combat the propagation of phytopathogenic Macrophomina phaseolina [110], since this species is known to cause significant damages in food crops, including plants used in human diets $[14,52,111,112]$. Khan and colleagues found a general inhibitory activity against this species in the extracts of green, brown, and red algae [52]. However, a higher activity from the aqueous and methanolic extracts obtained from Sargassum tenerrinum was registered. Despite the common existence of some differences between algae species from the same genus [52], Sargassum ilicifolium [109], S. swartzii [71], and S. binderi [74] have also demonstrated potential to inhibit $M$. phaseolina growth. Among brown algae, relevant inhibitory activity was also revealed by Cystoseira indica [109], Dictyota indica, Padina tetrastomatica, S. polypodioides (previously identified as S. marginatum) [71], Stokeyia indica, and Spatoglossum variabile $[72,74]$. As reported above for Fusarium, the brown algae extracts seem to be more effective than the remaining algae groups, which may be due to the presence of polyphenols [52] and/or 1-aminocyclopropane-1-carboxylic acid [71,113], which may also be the reason for their activity against M. phaseolina. The effectiveness of the dry powder obtained from Melanothamnus afaqhusainii [72,74] and S. robusta [71] demonstrated the potential of red algae in planta assays. The potential of the Rhodophyta group was also confirmed in vitro, namely, with Centroceras sp., Ceramium sp., Gelidium pulchrumi, Gracilaria corticate, Halymenia porphyriformis, Hypnea musciformis, Jania pedunculata var. adhaerens, Neoporphyra perforate, and Osmundea pinnatifida [52], which presented antifungal activity against $M$. phaseolina. Though to a lesser extent, the antifungal activity of green algae against this fungus species was also demonstrated in vitro with C. racemosa, C. taxifolia, Chaetomorpha antennina, Codium indicum, Udotea sp., and Ulva rigida [52], and also in planta using dry powder Rhizoclonium implexum and H. tuna [71,74]. Some of the compounds associated with the antifungal activity from macroalgae extracts are the volatile compounds in the essential oils [72], namely alcohols, aldehydes, carboxylic acids, ketones, esters, and hydrocarbons [114].

Similar to the studies performed with Fusarium species and M. phaseolina, Khan [52] also tested a diverse set of algae extracts against the growth of the soil-borne fungus Rhizoctonia solani [52]. Susceptibility to red, green, and brown algae was observed, but to a lesser extent than when the extracts were obtained using water instead of methanol [52]. Curiously, for some of the macroalgae, inhibitory activity was observed only with the methanolic extracts. The suppression of this fungus was influenced by the different compounds, which resulted from the use of different solvents during the macroalgae extraction procedure, highlighting the type of extraction as a major factor in obtaining antifungal compounds, with the methanolic extracts presenting an overall higher activity [52]. In the same study, a predominance of brown algae exhibiting antifungal activity (Table 2) was observed. This is in agreement with the high diversity of classes of compounds typically found in brown algae, confirming their compositional diversity and revealing their antifungal bioactivities [52]. This capacity is usually associated with phenolic compounds, specifically phlorotannins, which are very abundant in Phaeophyceae algae, and also with crinitol, an acyclic diterpene alcohol already described with antimicrobial activity against a wide range of microorganisms $[115,116]$. Recently, the chemical characterization by gas chromatography coupled to mass spectroscopy (GC-MS), of a brown alga extract, 
Sargassum tenerrimum, possessing inhibitory activity against spore germination/growth of R. solani, demonstrated a high abundance of $\mathrm{n}$-hexadecanoic acid [79]. Considering the vestigial quantities of the remaining compounds analysed, the antifungal activity presented by $S$. tenerrimum was associated with this saturated long-chain fatty acid. However, this does not remove the need for more compositional tests with the remaining algae that also presented activity [79], as well as the isolation and analysis of specific compounds, to unravel the molecular mechanism underlying the antifungal activity of macroalgae extracts. Promising results were also obtained in planta with the crude algae and extracts obtained from a diverse group of green, red, and brown seaweeds against $R$. solani infection of soybean and pepper plants [71], eggplant, watermelon [72], cotton crops [74], sunflower, and tomato plants [75].

Table 2. Compilation of the best antifungal activities of macroalgae extracts against phytopathogenic fungi obtained using in vitro methodologies (summary of the information available in Scopus up until 25 February 2021). Detailed information regarding the results obtained for each study can be consulted in Supplementary Tables S1-S10. * Algae species not found in the Algaebase database.

\begin{tabular}{|c|c|c|c|}
\hline Phytopathogenic Fungi & Host Species & Methodology & Reference \\
\hline \multirow{2}{*}{ Alternaria alternata } & Hormophysa cuneiformis & $\begin{array}{l}\text { Agar diffusion assay/Broth } \\
\text { microdilution assay }\end{array}$ & [56] \\
\hline & Ulva lactuca & Disc diffusion technique & [58] \\
\hline \multirow{2}{*}{ Aspergillus fumigatus } & Anthophycus longifolius & Well diffusion technique & [51] \\
\hline & Osmundea pinnatifida & Radial growth inhibition & [117] \\
\hline \multirow{2}{*}{ Aspergillus niger } & Anthophycus longifolius & Well diffusion technique & [51] \\
\hline & Ulva lactuca & Disc diffusion technique & [58] \\
\hline Aspergillus terreus & Anthophycus longifolius & Well diffusion technique & [51] \\
\hline Botrytis cinerea & Dictyopteris polypodioides & Agar diffusion technique & {$[63]$} \\
\hline Cladosporium herbarum & Hormophysa cuneiformis & $\begin{array}{l}\text { Agar diffusion assay/Broth } \\
\text { microdilution assay }\end{array}$ & [56] \\
\hline \multirow{3}{*}{ Colletotrichum acutatum } & Dictyota dichotoma & Disc diffusion technique & {$[65]$} \\
\hline & Dictyota implexa & Disc diffusion technique & [65] \\
\hline & Dictyota spiralis & Disc diffusion technique & {$[65]$} \\
\hline \multirow{3}{*}{ Colletotrichum falcatum } & Caulerpa racemosa & Poisoned food technique & [66] \\
\hline & Hydropuntia edulis & Poisoned food technique & [66] \\
\hline & Sargassum myricocystum * & Poisoned food technique & [66] \\
\hline \multirow{6}{*}{ Colletotrichum gloeosporioides } & Hypnea musciformis & Disc diffusion technique & {$[67,68]$} \\
\hline & Kappaphycus alvarezii & Poisoned food technique & [69] \\
\hline & Laurencia dendroidea & Disc diffusion technique & {$[67]$} \\
\hline & Ochtodes secundiramea & Disc diffusion technique & {$[67,68]$} \\
\hline & Palisada flagellifera & Disc diffusion technique & {$[68]$} \\
\hline & Pterocladiella capillacea & Disc diffusion technique & {$[67]$} \\
\hline \multirow{5}{*}{ Colletotrichum musae } & Hypnea musciformis & Poisoned food technique & [67] \\
\hline & Laurencia dendroidea & Poisoned food technique & [67] \\
\hline & Ochtodes secundiramea & Poisoned food technique & [67] \\
\hline & Padina gymnospora & Poisoned food technique & [67] \\
\hline & Pterocladiella capillacea & Poisoned food technique & [67] \\
\hline
\end{tabular}


Table 2. Cont.

\begin{tabular}{|c|c|c|c|}
\hline Phytopathogenic Fungi & Host Species & Methodology & Reference \\
\hline Fusarium culmorum & Fucus vesiculosus & $\begin{array}{c}\text { Inhibition of mycelial } \\
\text { growth/Macroconidia germination } \\
\text { inhibition }\end{array}$ & [57] \\
\hline Fusarium graminearum & Dictyopteris polypodioides & Agar diffusion technique & [63] \\
\hline \multirow{2}{*}{ Fusarium moniliforme } & Botryocladia leptopoda & Test tube in agar & [96] \\
\hline & Dictyota hauckiana & Test tube in agar & [96] \\
\hline \multirow{30}{*}{ Fusarium oxysporum } & Asparagopsis taxiformis & Well diffusion technique & [118] \\
\hline & Calliblepharis floresii * & Poisoned food technique & [52] \\
\hline & Caulerpa chemnitzia & Poisoned food technique & {$[52]$} \\
\hline & Caulerpa racemosa & Poisoned food technique & {$[52]$} \\
\hline & Caulerpa scalpelliformis & Poisoned food technique & [52] \\
\hline & Caulerpa taxifolia & Poisoned food technique & {$[52]$} \\
\hline & Centroceras sp. & Poisoned food technique & {$[52]$} \\
\hline & Ceramium sp. & Poisoned food technique & [52] \\
\hline & Chaetomorpha antennina & Poisoned food technique & [52] \\
\hline & Codium indicum & Poisoned food technique & [52] \\
\hline & Dictyopteris polypodioides & Agar diffusion technique & [63] \\
\hline & Dictyota dicotoma & Poisoned food technique & [52] \\
\hline & Gelidium pulchrum & Poisoned food technique & [52] \\
\hline & Gracilaria corticata & Poisoned food technique & {$[52]$} \\
\hline & Halimeda tuna & $\begin{array}{l}\text { Poisoned food technique/Field } \\
\text { studies }\end{array}$ & {$[52,71]$} \\
\hline & Halymenia porphyriformis & Poisoned food technique & {$[52]$} \\
\hline & Hormophysa cuneiformis & $\begin{array}{l}\text { Agar diffusion assay / Broth } \\
\text { microdilution assay }\end{array}$ & [56] \\
\hline & Hypnea musciformis & Poisoned food technique & [52] \\
\hline & Jania pedunculata var. adhaerens & Poisoned food technique & [52] \\
\hline & Jolyna laminariodes & Poisoned food technique & {$[52]$} \\
\hline & Melanothamnus afaqhusainii & $\begin{array}{l}\text { Poisoned food technique/Field } \\
\text { studies }\end{array}$ & {$[52,72]$} \\
\hline & Neoporphyra perforata & Poisoned food technique & [52] \\
\hline & Osmundea pinnatifida & Poisoned food technique & {$[52]$} \\
\hline & Padina boergesenii & Disc diffusion technique & [119] \\
\hline & Padina tetrastromatica & Poisoned food technique & {$[52,71]$} \\
\hline & Polycladia indica & $\begin{array}{l}\text { Poisoned food technique/Disc } \\
\text { diffusion technique }\end{array}$ & {$[52,71,72,109]$} \\
\hline & Polycladia myrica & Disc diffusion technique & [119] \\
\hline & Sargassum aquifolium & Poisoned food technique & [52] \\
\hline & Sargassum cinereum & Disc diffusion technique & [119] \\
\hline & Sargassum ilicifolium & Disc diffusion technique & [109] \\
\hline
\end{tabular}


Table 2. Cont.

\begin{tabular}{|c|c|c|c|}
\hline Phytopathogenic Fungi & Host Species & Methodology & Reference \\
\hline & Sargassum tenerrimum & Poisoned food technique & [52] \\
\hline & Sargassum wightii & Poisoned food technique & [52] \\
\hline & Scinaia huismanii & Poisoned food technique & [52] \\
\hline & Spatoglossum asperum & Disc diffusion assay & [120] \\
\hline & Steochospermum polypolides* & Poisoned food technique & [52] \\
\hline & Udotea sp. & Poisoned food technique & [52] \\
\hline & Ulva rigida & Poisoned food technique & [52] \\
\hline & Valaniopsis sp. * & Poisoned food technique & [52] \\
\hline \multirow{3}{*}{ Fusarium oxysporum albedinis } & Dictyota dichotoma & Disc diffusion technique & [65] \\
\hline & Dictyota implexa & Disc diffusion technique & [65] \\
\hline & Dictyota spiralis & Disc diffusion technique & [65] \\
\hline \multirow{3}{*}{ Fusarium oxysporum dianthi } & Dictyota dichotoma & Disc diffusion technique & [65] \\
\hline & Dictyota implexa & Disc diffusion technique & [65] \\
\hline & Dictyota spiralis & Disc diffusion technique & [65] \\
\hline \multirow{3}{*}{ Fusarium oxysporum f.sp. udum } & Caulerpa racemosa & Poisoned food technique & [105] \\
\hline & Hydropuntia edulis & Poisoned food technique & [105] \\
\hline & Sargassum myricocystum * & Poisoned food technique & [105] \\
\hline \multirow{3}{*}{ Fusarium oxysporum lycopersici } & Dictyota dichotoma & Disc diffusion technique & [65] \\
\hline & Dictyota implexa & Disc diffusion technique & [65] \\
\hline & Dictyota spiralis & Disc diffusion technique & [65] \\
\hline \multirow{17}{*}{ Fusarium solani } & Botryocladia leptopoda & Test tube in agar & [96] \\
\hline & Caulerpa racemosa & Test tube in agar & [96] \\
\hline & Caulerpa taxifolia & Test tube in agar & [96] \\
\hline & Champia compressa & Test tube in agar & [96] \\
\hline & Codium indicum & Test tube in agar & {$[96]$} \\
\hline & Gracilaria corticata & Test tube in agar & [96] \\
\hline & Hypnea musciformis & Test tube in agar & [96] \\
\hline & Hypnea valentiae & Test tube in agar & [96] \\
\hline & Osmundea pinnatifida & Test tube in agar & [96] \\
\hline & Padina antillarum & Test tube in agar & [96] \\
\hline & Sarconema filiforme & Test tube in agar & [96] \\
\hline & Sargassum ilicifolium & Test tube in agar & [96] \\
\hline & Sargassum vulgare & Test tube in agar & {$[96,121]$} \\
\hline & Solieria robusta & Test tube in agar/Field studies & {$[71,74,96,121]$} \\
\hline & Spatoglossum asperum & Disc diffusion assay & [120] \\
\hline & Stoechospermum polypodioides & Test tube in agar/Field studies & {$[71,74,96]$} \\
\hline & Ulva lactuca & Test tube in agar & [96] \\
\hline Fusarium sp. & Anthophycus longifolius & Well diffusion technique & [51] \\
\hline \multirow{3}{*}{ Ganoderma boninense } & Caulerpa lamourouxii & Poisoned food technique & [122] \\
\hline & Caulerpa racemosa & Poisoned food technique & [122] \\
\hline & Halimeda macrophysa & Poisoned food technique & [122] \\
\hline
\end{tabular}


Table 2. Cont.

\begin{tabular}{|c|c|c|c|}
\hline Phytopathogenic Fungi & Host Species & Methodology & Reference \\
\hline & Sargassum oligocystum & Poisoned food technique & {$[122]$} \\
\hline Geotrichum sp. & Dictyopteris polypodioides & Agar diffusion technique & [63] \\
\hline \multirow{18}{*}{ Macrophomina phaseolina } & Calliblepharis floresii * & Poisoned food technique & [52] \\
\hline & Caulerpa racemosa & Poisoned food technique & [52] \\
\hline & Caulerpa taxifolia & Poisoned food technique & [52] \\
\hline & Centroceras sp. & Poisoned food technique & [52] \\
\hline & Ceramium sp. & Poisoned food technique & [52] \\
\hline & Chaetomorpha antennina & Poisoned food technique & {$[52]$} \\
\hline & Codium indicum & Poisoned food technique & {$[52]$} \\
\hline & Dictyota dicotoma & Poisoned food technique & {$[52]$} \\
\hline & Gelidium pulchrum & Poisoned food technique & [52] \\
\hline & Gracilaria corticata & Poisoned food technique & [52] \\
\hline & Halymenia porphyriformis & Poisoned food technique & {$[52]$} \\
\hline & Hypnea musciformis & Poisoned food technique & [52] \\
\hline & Jania pedunculata var. adhaerens & Poisoned food technique & [52] \\
\hline & Jolyna laminariodes & Poisoned food technique & [52] \\
\hline & Melanothamnus afaqhusainii & Poisoned food technique & [52] \\
\hline & Neoporphyra perforata & Poisoned food technique & [52] \\
\hline & Osmundea pinnatifida & Poisoned food technique & [52] \\
\hline & Padina tetrastromatica & Poisoned food technique & {$[52]$} \\
\hline \multirow{11}{*}{ Macrophomina phaseolina } & Polycladia indica & $\begin{array}{l}\text { Poisoned food technique/Disc } \\
\text { diffusion technique }\end{array}$ & {$[52,109]$} \\
\hline & Sargassum aquifolium & Poisoned food technique & [52] \\
\hline & Sargassum ilicifolium & Disc diffusion technique & [109] \\
\hline & Sargassum tenerrimum & Poisoned food technique & [52] \\
\hline & Sargassum wightii & Poisoned food technique & {$[52]$} \\
\hline & Scinaia huismanii & Poisoned food technique & [52] \\
\hline & Spatoglossum asperum & Disc diffusion assay & [120] \\
\hline & Stoechospermum polypodioides & Poisoned food technique & [52] \\
\hline & Udotea sp. & Poisoned food technique & [52] \\
\hline & Ulva rigida & Poisoned food technique & [52] \\
\hline & Valaniopsis sp. * & Poisoned food technique & [52] \\
\hline \multirow{5}{*}{ Mucor sp. } & Champia compressa & Test tube in agar & [96] \\
\hline & Hypnea musciformis & Test tube in agar & [96] \\
\hline & Sargassum boveanum & Test tube in agar & [96] \\
\hline & Sargassum ilicifolium & Test tube in agar & [96] \\
\hline & Ulva lactuca & Test tube in agar & [96] \\
\hline Penicillium expansum & Ulva lactuca & Disc diffusion technique & [58] \\
\hline \multirow{2}{*}{ Penicillium sp. } & Dictyota dichotoma & Disc diffusion technique & [123] \\
\hline & Ulva lactuca & Disc diffusion technique & [123] \\
\hline
\end{tabular}


Table 2. Cont.

\begin{tabular}{|c|c|c|c|}
\hline Phytopathogenic Fungi & Host Species & Methodology & Reference \\
\hline Penicillum digitatum & Hormophysa cuneiformis & $\begin{array}{c}\text { Agar diffusion assay/Broth } \\
\text { microdilution assay }\end{array}$ & [56] \\
\hline \multirow{3}{*}{ Phialophora cinerescens } & Dictyota dichotoma & Disc diffusion technique & [65] \\
\hline & Dictyota implexa & Disc diffusion technique & [65] \\
\hline & Dictyota spiralis & Disc diffusion technique & [65] \\
\hline \multirow{3}{*}{ Phoma tracheiphila } & Dictyota dichotoma & Disc diffusion technique & [65] \\
\hline & Dictyota implexa & Disc diffusion technique & [65] \\
\hline & Dictyota spiralis & Disc diffusion technique & [65] \\
\hline Pseudocercospora fijiensis & Halymenia floresii & Minimum inhibitory concentration & [94] \\
\hline \multirow{2}{*}{ Pyricularia oryzae } & Rhodomela confervoides & Spore spreading method & [95] \\
\hline & Symphyocladia latiuscula & Spore spreading method & [95] \\
\hline \multirow{18}{*}{ Rhizoctonia solani } & Calliblepharis floresii & Poisoned food technique & [52] \\
\hline & Centroceras sp. & Poisoned food technique & [52] \\
\hline & Ceramium sp. & Poisoned food technique & [52] \\
\hline & Chaetomorpha antennina & Poisoned food technique & [52] \\
\hline & Codium indicum & Poisoned food technique & [52] \\
\hline & Dictyopteris undulata & Fungitoxic activity & [92] \\
\hline & Gelidium pulchrum & Poisoned food technique & [52] \\
\hline & Gracilaria corticata & Poisoned food technique & [52] \\
\hline & Halymenia porphyriformis & Poisoned food technique & [52] \\
\hline & Hypnea musciformis & Poisoned food technique & [52] \\
\hline & Jania pedunculata var. adhaerens & Poisoned food technique & [52] \\
\hline & Melanothamnus afaqhusainii & Poisoned food technique & [52] \\
\hline & Neoporphyra perforata & Poisoned food technique & [52] \\
\hline & Osmundea pinnatifida & Poisoned food technique & [52] \\
\hline & Padina tetrastromatica & Poisoned food technique & [52] \\
\hline & Polycladia indica & Poisoned food technique & [52] \\
\hline & Sargassum aquifolium & Poisoned food technique & {$[52,71,74]$} \\
\hline & Sargassum tenerrimum & Poisoned food technique & {$[52,71]$} \\
\hline \multirow{7}{*}{ Rhizoctonia solani } & Sargassum wightii & Poisoned food technique & {$[52]$} \\
\hline & Spatoglossum asperum & Disc diffusion assay/Field studies & {$[73,120]$} \\
\hline & Stoechospermum polypodioides & $\begin{array}{c}\text { Poisoned food technique/Field } \\
\text { studies }\end{array}$ & {$[52,71,74]$} \\
\hline & Udotea sp. & Poisoned food technique & [52] \\
\hline & Ulva rigida & Poisoned food technique & [52] \\
\hline & Valaniopsis sp. * & Poisoned food technique & {$[52]$} \\
\hline & Dictyota dichotoma & $\begin{array}{l}\text { Disc diffusion technique/Spore } \\
\text { germination }\end{array}$ & {$[79]$} \\
\hline
\end{tabular}


Table 2. Cont

\begin{tabular}{|c|c|c|c|}
\hline Phytopathogenic Fungi & Host Species & Methodology & Reference \\
\hline & Padina gymnospora & $\begin{array}{l}\text { Disc diffusion technique/Spore } \\
\text { germination }\end{array}$ & [79] \\
\hline & Sargassum muticum & $\begin{array}{l}\text { Disc diffusion technique/Spore } \\
\text { germination }\end{array}$ & [79] \\
\hline & Sargassum tenerrimum & $\begin{array}{l}\text { Disc diffusion technique/Spore } \\
\text { germination }\end{array}$ & [79] \\
\hline & Sargassum wightii & $\begin{array}{l}\text { Disc diffusion technique/Spore } \\
\text { germination }\end{array}$ & [79] \\
\hline Sclerotinia sclerotiorum & Dictyopteris undulata & Fungitoxic activity & [92] \\
\hline Sclerotium rolfsii & Dictyopteris undulata & Fungitoxic activity & [92] \\
\hline \multirow{3}{*}{ Verticillium dahliae } & $\begin{array}{l}\text { Cystoseira humilis var. } \\
\text { myriophylloides }\end{array}$ & Poisoned food technique & [93] \\
\hline & Dictyopteris polypodioides & Agar diffusion technique & [63] \\
\hline & Fucus spiralis & Poisoned food technique & [93] \\
\hline
\end{tabular}

\subsubsection{Potential Antifungal Mechanisms}

The mode of action of antifungal compounds extracted by macroalgae is still poorly understood. Generally, a fungus can be affected by compounds directly targeting the cell wall or membrane, two important components that contact with the exterior environment, or intracellular organelles, such as nucleic acids or mitochondria. Antifungal agents that enter into the cell can disrupt protein synthesis by their interaction with nucleic acids [124], as well as disturb the homeostasis and stability of the cell by interfering with the mitochondrial respiratory chain $[125,126]$.

An important target usually affected by commercial antifungal products is the fungal membrane $[124,126]$. The cell membrane is a primary and crucial component for guaranteeing cellular stability in a fungal organism [53]. Abnormalities and events occurring at the membrane level can disturb cell stability, leading to the reduction of cell lifespan [127]. Fatty acids are a vast and diversified group of compounds present in macroalgae and have been mentioned several times throughout this work due to their antifungal potential. The unique composition of fatty acids, characterized by the presence of a carboxyl group at one end and a methyl group at the other chain end, allows their insertion into the fungal membrane, promoting an increase of fluidity and, consequently, their permeability, modifying their conformational organization and culminating in cell death [54]. This antifungal mechanism was demonstrated by Hajlaou and colleagues against relevant fungal species, such as Cladosporium cucumerinum, B. cinerea and Fusarium oxysporum f.sp. radicislycopersici [128], affecting conidia germination and fungal biomass production.

Another antifungal mechanism proposed is related to sterol present in the fungal membrane. Some algae compounds have the capacity to interact/inhibit sterol synthesis [124]. One example is observed with the algae-based products of $F$. vesiculosus, presenting a high content of fucosterol, a natural sterol isolated from brown algae, known to possess fungistatic and antifungal activity against F. culmorum [57]. The similarity of this algae-derived sterol (Figure 1) with ergosterol (Figure 2) (a sterol in the fungal membrane, responsible for stability) allows the interaction of fucosterol with fungal membrane modulators to disturb their normal regulation (Figure 3) [129], as well as the increase of the fluidity of the membrane components [53]. 


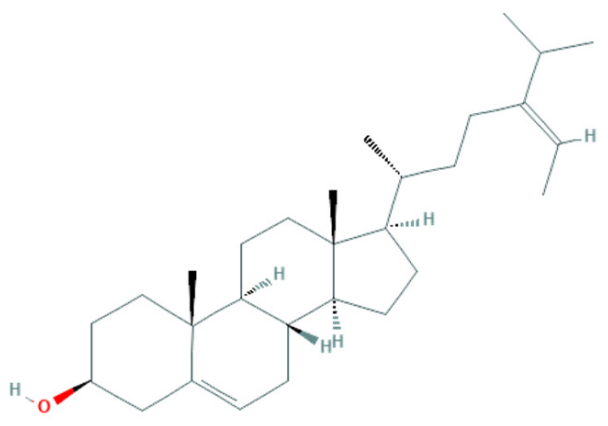

Figure 1. Fucosterol $\left(\mathrm{C}_{29} \mathrm{H}_{48} \mathrm{O}\right)$. Chemical structure obtained from PubChem database on 4 August 2021 (https: / / pubchem.ncbi.nlm.nih.gov / compound /5281328\#section=2D-structure).



Figure 2. Ergosterol $\left(\mathrm{C}_{28} \mathrm{H}_{44} \mathrm{O}\right)$. Chemical structure obtained from PubChem database 4 August 2021 (https: / / pubchem.ncbi.nlm.nih.gov / compound /444679\#section=2D-structure).

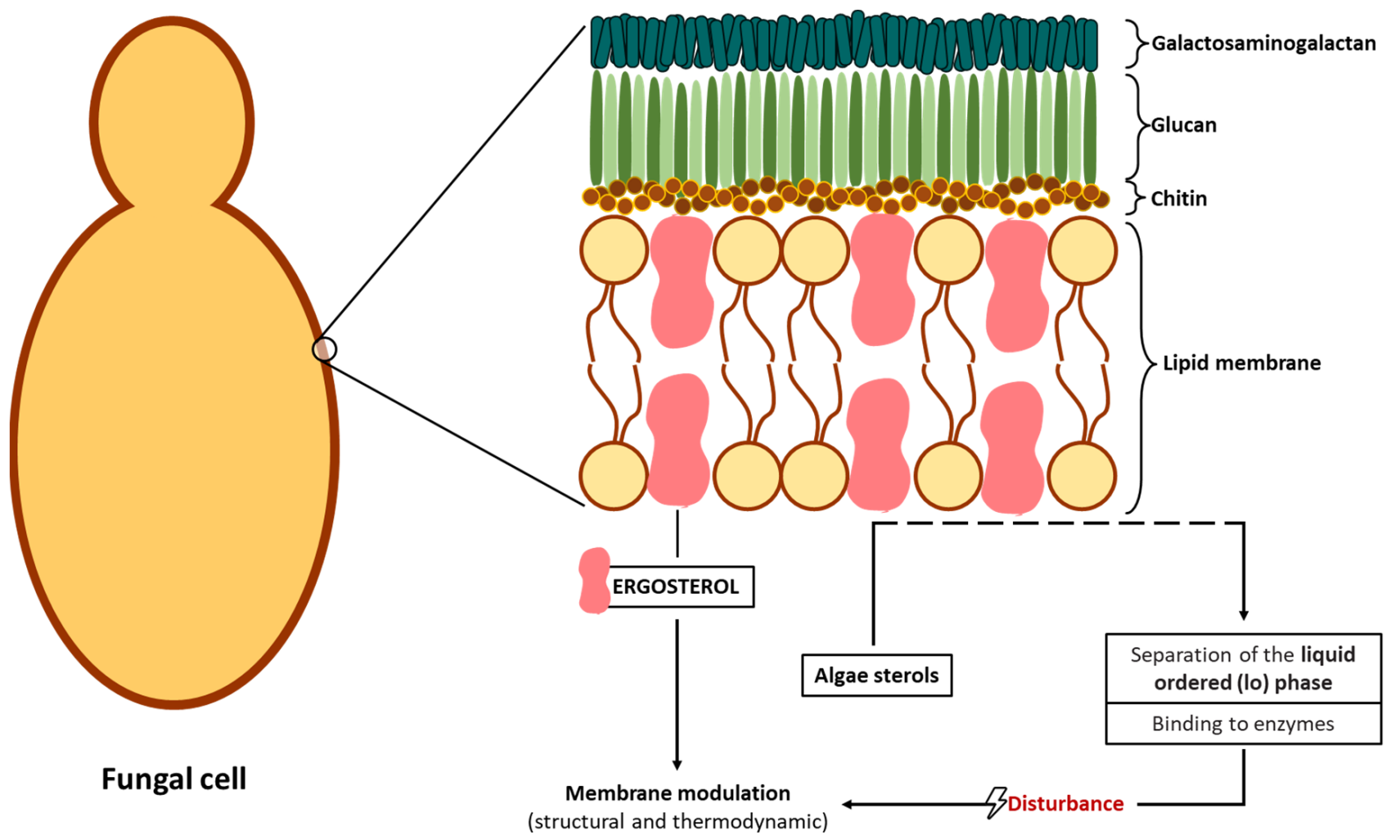

Figure 3. Schematic representation of a possible interaction of algae sterols in the fungal membrane. 
Another antifungal mechanism is demonstrated by Candida spp. [130] against filamentous phytopathogenic fungi. This action is related to the chemical characterization of unsaturated fatty acids (defined by one or more $\mathrm{C}=\mathrm{C}$ bond/s), which can improve the antifungal action of these compounds. This property is associated with the easy incorporation of polyunsaturated lipids into the fungal membrane, which also contributes to the destabilization of cell structure, triggering events of oxidative stress [128] known to act against several species of phytopathogenic fungi, such as Alternaria solani, A. niger, B. cinerea, C. cucumerinum, F. oxysporum, and Rh. solani [53].

Another important group of compounds presenting antifungal potential are phenolic compounds. Among them, phlorotannins are highlighted as one of the relevant antifungal compounds of brown algae, as presented above. However, the antifungal mechanism of these compounds has only been clarified for yeast species [126,131].

\section{In Planta Studies: Are These Assays Enough to Prove the Antifungal Potential of the Extracts?}

The assays performed in vivo, in this case with the use of algae extracts on the host plant, are a peculiar case of a complex analysis, more difficult than in vitro assays. The suppression of infection/colonies in the host tissues can be a consequence of two possible situations: (1) a direct antifungal action over the phytopathogenic agent, or (2) an elicitation, promoting the activation of defense pathways of the plant.

Table 3 presents the most relevant assays performed in field/greenhouse conditions against fungal phytopathogenic species. Several studies have demonstrated the antifungal potential of dry powder macroalgae in field/greenhouse conditions against several phytopathogenic fungi, such as Fusarium species. Ehteshamul-Haque and colleagues [71] tested the inhibition potential of the brown algae Dictyota cervicornis (identified as Dictyota indica), Padina tetrastromatica, Stoechospermum polypodioides (then identified as Stoechospermum marginatum), Polycladia indica (as Stokeyia indica), Sargassum swartzii, the red alga Solieria robusta, and the green alga Halimeda tuna against the root-rotting fungi Fusarium spp., in Glycine max Merrill and Capsicum annuum plants [71]. 1-Aminocyclopropane-1-carboxylic acid (ACC) was suggested to be responsible for the antimicrobial activity displayed by the algae $[71,72,75]$, but the lack of an in vitro test hampers this conclusion. Thus, it is of major importance to combine both in vivo and in vitro tests in order to better understand the interaction between the extract, fungal phytopathogen, and host.

Table 3. Compilation of the best results obtained by macroalgae extracts/dry powder against plants infected with phytopathogenic fungi using in field methodologies (summary of the information available in Scopus up until 25 February 2021). * Infection expressed in \% of infection after application of the macroalgae extract. A: The antimicrobial activity can be due the presence of acrylic acid; B: Increase in effectiveness after a second application; C: Loss of effectiveness for long periods.

\begin{tabular}{|c|c|c|c|c|c|c|c|}
\hline \multirow{2}{*}{$\begin{array}{l}\text { Phytopathogenic } \\
\text { Fungi }\end{array}$} & \multirow{2}{*}{$\begin{array}{l}\text { Macroalgae } \\
\text { Source }\end{array}$} & \multirow{2}{*}{$\begin{array}{c}\text { Extract } \\
\text { Type/Concentration }\end{array}$} & \multicolumn{2}{|c|}{ In field Assays } & \multicolumn{2}{|c|}{$\begin{array}{c}\text { Greenhouse Assays } \\
\text { Green }\end{array}$} & \multirow{2}{*}{ References } \\
\hline & & & Host & Infection * & Host & Infection * & \\
\hline \multirow{9}{*}{$\begin{array}{l}\text { Fusarium } \\
\text { oxysporum }\end{array}$} & Dictyota cervicornis & Dry powder & Glycine $\max$ (L.) & 6.2 & - & - & [71] \\
\hline & Halimeda tuna & Dry powder & Glycine max (L.) & 0 & - & - & [71] \\
\hline & \multirow{2}{*}{$\begin{array}{l}\text { Melanothamnus } \\
\text { afaghusainii }\end{array}$} & Dry powder & Eggplant & 0 & - & - & [72] \\
\hline & & Dry powder & Watermelon & 0 & - & - & [72] \\
\hline & $\begin{array}{c}\text { Padina } \\
\text { tetrastromatica }\end{array}$ & Dry powder & Glycine max (L.) & 0 & - & - & [71] \\
\hline & \multirow{2}{*}{ Polycladia indica } & Dry powder & Eggplant & 0 & - & - & [72] \\
\hline & & Dry powder & Watermelon & 0 & - & - & [72] \\
\hline & Sargassum swartzii & Dry powder & Glycine $\max$ (L.) & 12.5 & - & - & [71] \\
\hline & Solieria robusta & Dry powder & Glycine $\max$ (L.) & 0 & - & - & [71] \\
\hline
\end{tabular}


Table 3. Cont.

\begin{tabular}{|c|c|c|c|c|c|c|c|}
\hline \multirow{2}{*}{$\begin{array}{c}\text { Phytopathogenic } \\
\text { Fungi }\end{array}$} & \multirow{2}{*}{$\begin{array}{l}\text { Macroalgae } \\
\text { Source }\end{array}$} & \multirow{2}{*}{$\begin{array}{c}\text { Extract } \\
\text { Type/Concentration }\end{array}$} & \multicolumn{2}{|c|}{ In field Assays } & \multicolumn{2}{|c|}{$\begin{array}{c}\text { Greenhouse Assays } \\
\text { Green }\end{array}$} & \multirow{2}{*}{ References } \\
\hline & & & Host & Infection * & Host & Infection * & \\
\hline & $\begin{array}{l}\text { Spatoglossum } \\
\text { variabile }\end{array}$ & Dry powder & Eggplant & 0 & - & - & [72] \\
\hline & $\begin{array}{l}\text { Stoechospermum } \\
\text { polypodioides }\end{array}$ & Dry powder & Glycine max (L.) & 0 & - & - & [71] \\
\hline \multirow{23}{*}{ Fusarium solani } & Dictyota cervicornis & Dry powder & Glycine max (L.) & 0 & $\begin{array}{l}\text { Glycine } \\
\max (\mathrm{L} .)\end{array}$ & 6.2 & [71] \\
\hline & \multirow{3}{*}{ Halimeda tuna } & Dry powder & $\begin{array}{l}\text { Gossypium } \\
\text { hirsutum L. }\end{array}$ & 0 & $\begin{array}{l}\text { Gossypium } \\
\text { hirsutum L. }\end{array}$ & 12.5 & [74] \\
\hline & & Dry powder & Sunflower & 0 & $\begin{array}{l}\text { Glycine } \\
\max (\mathrm{L} .)\end{array}$ & 12.5 & [71] \\
\hline & & Dry powder & - & - & $\begin{array}{l}\text { Lycopersicum } \\
\text { esculentum }\end{array}$ & $12.5^{\mathrm{A}}$ & [75] \\
\hline & $\begin{array}{c}\text { Melanothamnus } \\
\text { afaqhusainii }\end{array}$ & Dry powder & $\begin{array}{l}\text { Lycopersicum } \\
\text { esculentum }\end{array}$ & $0^{\mathrm{A}}$ & Sunflower & $25^{\mathrm{A}}$ & [75] \\
\hline & \multirow{2}{*}{$\begin{array}{c}\text { Padina } \\
\text { tetrastromatica }\end{array}$} & Dry powder & Glycine max (L.) & 0 & $\begin{array}{l}\text { Glycine } \\
\max (\mathrm{L} .)\end{array}$ & 12.5 & [71] \\
\hline & & Dry powder & Capsicum annum $\mathrm{L}$. & 0 & - & - & [71] \\
\hline & \multirow[b]{2}{*}{ Polycladia indica } & Dry powder & Capsicum annum L. & 6.2 & $\begin{array}{l}\text { Glycine } \\
\max (\mathrm{L} .)\end{array}$ & 18.7 & [71] \\
\hline & & Dry powder & $\begin{array}{l}\text { Gossypium } \\
\text { hirsutum L. }\end{array}$ & 12.5 & $\begin{array}{l}\text { Gossypium } \\
\text { hirsutum L. }\end{array}$ & 6.2 & [74] \\
\hline & $\begin{array}{l}\text { Rhizoclonium } \\
\text { riparium }\end{array}$ & Dry powder & $\begin{array}{l}\text { Gossypium } \\
\text { hirsutum L. }\end{array}$ & $18.7^{\mathrm{C}}$ & $\begin{array}{l}\text { Gossypium } \\
\text { hirsutum L. }\end{array}$ & 18.7 & [74] \\
\hline & $\begin{array}{l}\text { Sargassum } \\
\text { aquifolium }\end{array}$ & Dry powder & Capsicum annum L. & 6.2 & $\begin{array}{l}\text { Gossypium } \\
\text { hirsutum L. }\end{array}$ & 6.2 & {$[71,74]$} \\
\hline & \multirow{3}{*}{ Sargassum swartzii } & Dry powder $(0.5 \%)$ & - & - & $\begin{array}{l}\text { Lycopersicum } \\
\text { esculentum }\end{array}$ & 31.2 & [73] \\
\hline & & Dry powder $(1 \%)$ & - & - & $\begin{array}{l}\text { Lycopersicum } \\
\text { esculentum }\end{array}$ & 12.5 & [73] \\
\hline & & Dry powder & Glycine max (L.) & $0^{\mathrm{C}}$ & $\begin{array}{l}\text { Glycine } \\
\max (\mathrm{L} .)\end{array}$ & 6.2 & [71] \\
\hline & $\begin{array}{l}\text { Sargassum } \\
\text { tenerrimum }\end{array}$ & Dry powder & Capsicum annum $\mathrm{L}$. & $6.2^{\mathrm{B}}$ & - & - & [71] \\
\hline & \multirow{2}{*}{ Solieria robusta } & Dry powder & Glycine max (L.) & $6.2^{\mathrm{C}}$ & $\begin{array}{l}\text { Glycine } \\
\max (\mathrm{L} .)\end{array}$ & 0 & [71] \\
\hline & & Dry powder & Capsicum annuum L. & $0^{\mathrm{B}}$ & $\begin{array}{l}\text { Gossypium } \\
\text { hirsutum L. }\end{array}$ & 12.5 & {$[71,74]$} \\
\hline & $\begin{array}{c}\text { Spatoglossum } \\
\text { asperum }\end{array}$ & Dry powder $(0.5 \%)$ & $\begin{array}{l}\text { Solanum } \\
\text { melongena } \mathrm{L} \text {. }\end{array}$ & 18.7 & - & - & [72] \\
\hline & \multirow{3}{*}{$\begin{array}{l}\text { Spatoglossum } \\
\text { variabile }\end{array}$} & Dry powder & $\begin{array}{c}\text { Citrullus lanatus } \\
\text { (Thunb.) Matsum. \& } \\
\text { Nakai }\end{array}$ & 18.7 & $\begin{array}{l}\text { Gossypium } \\
\text { hirsutum L. }\end{array}$ & 18.7 & {$[72,74]$} \\
\hline & & Dry powder & Sunflower & $0^{\mathrm{A}}$ & Sunflower & $18.7^{\mathrm{A}}$ & [75] \\
\hline & & Dry powder & $\begin{array}{l}\text { Lycopersicum } \\
\text { esculentum }\end{array}$ & $0^{\mathrm{A}}$ & $\begin{array}{l}\text { Lycopersicum } \\
\text { esculentum }\end{array}$ & $12.5^{\mathrm{A}}$ & [75] \\
\hline & \multirow{2}{*}{$\begin{array}{l}\text { Stoechospermum } \\
\text { polypodioides }\end{array}$} & Dry powder & Glycine max (L.) & $0^{\mathrm{C}}$ & $\begin{array}{l}\text { Glycine } \\
\max (\mathrm{L} .)\end{array}$ & 12.5 & [71] \\
\hline & & Dry powder & Capsicum annuиm L. & 6.2 & $\begin{array}{l}\text { Gossypium } \\
\text { hirsutum L. }\end{array}$ & 18.7 & {$[71,75]$} \\
\hline
\end{tabular}


Table 3. Cont.

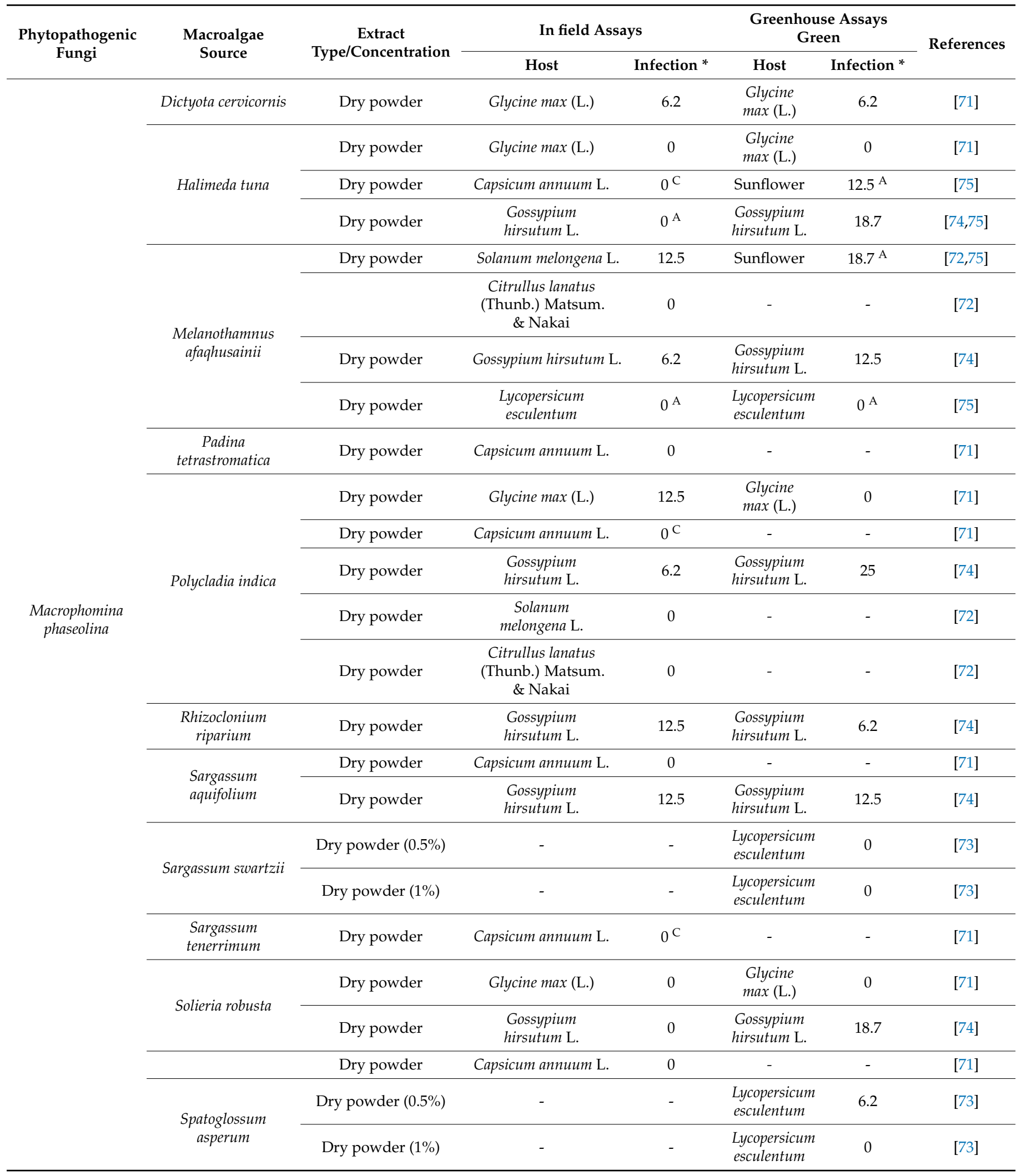


Table 3. Cont.

\begin{tabular}{|c|c|c|c|c|c|c|c|}
\hline \multirow{2}{*}{$\begin{array}{c}\text { Phytopathogenic } \\
\text { Fungi }\end{array}$} & \multirow{2}{*}{$\begin{array}{l}\text { Macroalgae } \\
\text { Source }\end{array}$} & \multirow{2}{*}{$\begin{array}{c}\text { Extract } \\
\text { Type/Concentration }\end{array}$} & \multicolumn{2}{|c|}{ In field Assays } & \multicolumn{2}{|c|}{$\begin{array}{c}\text { Greenhouse Assays } \\
\text { Green }\end{array}$} & \multirow{2}{*}{ References } \\
\hline & & & Host & Infection * & Host & Infection * & \\
\hline & \multirow{5}{*}{$\begin{array}{l}\text { Spatoglossum } \\
\text { variabile }\end{array}$} & Dry powder & Sunflower & $0^{\mathrm{A}}$ & Sunflower & $0^{\mathrm{A}}$ & [75] \\
\hline & & Dry powder & $\begin{array}{l}\text { Lycopersicum } \\
\text { esculentum }\end{array}$ & 0 & $\begin{array}{l}\text { Lycopersicum } \\
\text { esculentum }\end{array}$ & 0 & [75] \\
\hline & & Dry powder & $\begin{array}{l}\text { Gossypium } \\
\text { hirsutum L. }\end{array}$ & 6.2 & $\begin{array}{l}\text { Gossypium } \\
\text { hirsutum L. }\end{array}$ & 6.2 & [74] \\
\hline & & Dry powder & $\begin{array}{l}\text { Solanum } \\
\text { melongena } \mathrm{L} \text {. }\end{array}$ & 0 & - & - & \\
\hline & & Dry powder & $\begin{array}{c}\text { Citrullus lanatus } \\
\text { (Thunb.) Matsum. } \\
\text { \& Nakai }\end{array}$ & 0 & - & - & [72] \\
\hline & \multirow{3}{*}{$\begin{array}{l}\text { Stoechospermum } \\
\text { polypodioides }\end{array}$} & Dry powder & Glycine max (L.) & $0^{\mathrm{C}}$ & $\begin{array}{l}\text { Glycine } \\
\max (\mathrm{L} .)\end{array}$ & 6.2 & [71] \\
\hline & & & $\begin{array}{l}\text { Gossypium } \\
\text { hirsutum L. }\end{array}$ & 0 & $\begin{array}{l}\text { Gossypium } \\
\text { hirsutum L. }\end{array}$ & 12.5 & [74] \\
\hline & & Dry powder & Capsicum annuum L. & 0 & - & - & [71] \\
\hline \multirow{18}{*}{ Rhizoctonia solani } & Dictyota cervicornis & Dry powder & Glycine max $\mathrm{L}$. & $6.2^{C}$ & $\begin{array}{l}\text { Glycine } \\
\max \mathrm{L} .\end{array}$ & 0 & [71] \\
\hline & \multirow{3}{*}{ Halimeda tuna } & Dry powder & Capsicum annuum L. & $0^{\mathrm{B}}$ & $\begin{array}{l}\text { Glycine } \\
\max \mathrm{L} .\end{array}$ & 0 & [71] \\
\hline & & & Sunflower & $0^{\mathrm{A}}$ & $\begin{array}{l}\text { Gossypium } \\
\text { hirsutum L. }\end{array}$ & 12.5 & {$[74,75]$} \\
\hline & & Dry powder & $\begin{array}{l}\text { Lycopersicum } \\
\text { esculentum }\end{array}$ & $12.5^{\mathrm{A}}$ & $\begin{array}{l}\text { Lycopersicum } \\
\text { esculentum }\end{array}$ & $6.2^{\mathrm{A}}$ & [75] \\
\hline & \multirow{2}{*}{$\begin{array}{l}\text { Melanothamnus } \\
\text { afaqhusainii }\end{array}$} & Dry powder & Citrullus lanatus & 0 & $\begin{array}{l}\text { Gossypium } \\
\text { hirsutum L. }\end{array}$ & 18.7 & {$[72,74]$} \\
\hline & & Dry powder & $\begin{array}{l}\text { Lycopersicum } \\
\text { esculentum }\end{array}$ & $12.5^{\mathrm{A}}$ & $\begin{array}{l}\text { Lycopersicum } \\
\text { esculentum }\end{array}$ & $6.2^{\mathrm{A}}$ & [75] \\
\hline & & Dry powder & - & - & Sunflower & 18.7 & [75] \\
\hline & \multirow{2}{*}{$\begin{array}{c}\text { Padina } \\
\text { tetrastromatica }\end{array}$} & Dry powder & Glycine $\max \mathrm{L}$. & $12.5^{\mathrm{C}}$ & $\begin{array}{l}\text { Glycine } \\
\max \mathrm{L} \text {. }\end{array}$ & 0 & [71] \\
\hline & & Dry powder & Capsicum annuиm L. & 0 & - & - & [71] \\
\hline & \multirow{4}{*}{ Polycladia indica } & Dry powder & $\begin{array}{l}\text { Solanum } \\
\text { melongena } \mathrm{L} \text {. }\end{array}$ & 0 & - & - & {$[71,72,74]$} \\
\hline & & Dry powder & $\begin{array}{l}\text { Citrullus lanatus } \\
\text { (Thunb.) Matsum. } \\
\text { \& Nakai }\end{array}$ & 12.5 & - & - & [72] \\
\hline & & Dry powder & Capsicum annuum $\mathrm{L}$. & 0 & $\begin{array}{l}\text { Glycine } \\
\max \mathrm{L} .\end{array}$ & 0 & [71] \\
\hline & & Dry powder & $\begin{array}{l}\text { Gossypium } \\
\text { hirsutum L. }\end{array}$ & 6.2 & $\begin{array}{l}\text { Gossypium } \\
\text { hirsutum L. }\end{array}$ & 12.5 & [74] \\
\hline & $\begin{array}{l}\text { Rhizoclonium } \\
\text { riparium }\end{array}$ & Dry powder & $\begin{array}{l}\text { Gossypium } \\
\text { hirsutum L. }\end{array}$ & 25 & $\begin{array}{l}\text { Gossypium } \\
\text { hirsutum L. }\end{array}$ & 25 & [74] \\
\hline & \multirow{2}{*}{$\begin{array}{l}\text { Sargassum } \\
\text { aquifolium }\end{array}$} & Dry powder & Capsicum annuum $\mathrm{L}$. & 0 & $\begin{array}{l}\text { Gossypium } \\
\text { hirsutum L. }\end{array}$ & 6.2 & {$[71,74]$} \\
\hline & & Dry powder & $\begin{array}{l}\text { Gossypium } \\
\text { hirsutum L. }\end{array}$ & 18.7 & - & - & [74] \\
\hline & \multirow{2}{*}{ Sargassum swartzii } & Dry powder $(0.5 \%)$ & - & - & $\begin{array}{l}\text { Lycopersicum } \\
\text { esculentum }\end{array}$ & 0 & {$[71,73]$} \\
\hline & & Dry powder (1\%) & - & - & $\begin{array}{l}\text { Lycopersicum } \\
\text { esculentum }\end{array}$ & 0 & {$[71,73]$} \\
\hline
\end{tabular}


Table 3. Cont.

\begin{tabular}{|c|c|c|c|c|c|c|c|}
\hline \multirow{2}{*}{$\begin{array}{c}\text { Phytopathogenic } \\
\text { Fungi }\end{array}$} & \multirow{2}{*}{$\begin{array}{l}\text { Macroalgae } \\
\text { Source }\end{array}$} & \multirow{2}{*}{$\begin{array}{c}\text { Extract } \\
\text { Type/Concentration }\end{array}$} & \multicolumn{2}{|c|}{ In field Assays } & \multicolumn{2}{|c|}{$\begin{array}{c}\text { Greenhouse Assays } \\
\text { Green }\end{array}$} & \multirow{2}{*}{ References } \\
\hline & & & Host & Infection * & Host & Infection * & \\
\hline & & Dry powder & - & - & $\begin{array}{l}\text { Glycine } \\
\max \mathrm{L} .\end{array}$ & 0 & [71] \\
\hline & $\begin{array}{l}\text { Sargassum } \\
\text { tenerrimum }\end{array}$ & Dry powder & Capsicum annuum $\mathrm{L}$. & $0^{\mathrm{C}}$ & - & - & [71] \\
\hline & \multirow{2}{*}{ Solieria robusta } & Dry powder & Capsicum annuum L. & 0 & $\begin{array}{l}\text { Glycine } \\
\max \mathrm{L} .\end{array}$ & 0 & [71] \\
\hline & & Dry powder & $\begin{array}{l}\text { Gossypium } \\
\text { hirsutum L. }\end{array}$ & 0 & $\begin{array}{l}\text { Gossypium } \\
\text { hirsutum L. }\end{array}$ & 12.5 & [74] \\
\hline & \multirow{2}{*}{$\begin{array}{l}\text { Spatoglossum } \\
\text { asperum }\end{array}$} & Dry powder $(0.5 \%)$ & - & - & $\begin{array}{l}\text { Lycopersicum } \\
\text { esculentum }\end{array}$ & 25 & [73] \\
\hline & & Dry powder (1\%) & - & - & $\begin{array}{l}\text { Lycopersicum } \\
\text { esculentum }\end{array}$ & 6.2 & [73] \\
\hline & \multirow{2}{*}{$\begin{array}{l}\text { Spatoglossum } \\
\text { variabile }\end{array}$} & Dry powder & $\begin{array}{l}\text { Citrullus lanatus } \\
\text { (Thunb.) Matsum. } \\
\text { \& Nakai }\end{array}$ & 0 & Sunflower & $12.5^{\mathrm{A}}$ & {$[72,75]$} \\
\hline & & Dry powder & $\begin{array}{l}\text { Lycopersicum } \\
\text { esculentum }\end{array}$ & $12.5^{\mathrm{A}}$ & $\begin{array}{l}\text { Lycopersicum } \\
\text { esculentum }\end{array}$ & $6.2^{\mathrm{A}}$ & [75] \\
\hline & $\begin{array}{l}\text { Stoechospermum } \\
\text { polypodioides }\end{array}$ & Dry powder & Capsicum annuиm L. & 0 & $\begin{array}{l}\text { Glycine } \\
\max \mathrm{L} .\end{array}$ & 0 & [71] \\
\hline
\end{tabular}

A similar situation to the one described in the first paragraph of this section was observed in another in planta assay. Despite the infection inhibition/suppression success obtained against $M$. phaseolina $[52,71,72,74]$ and $R$. solani $[71,72,74,75]$ after the application of a dry powder from a diverse group of green, red, and brown algae in plants such as soybean, pepper, eggplant, watermelon, cotton crops, sunflower, and tomato (greenhouse and/or field conditions), a direct antifungal activity cannot be attributed to the macroalgae based only on these assays. Additionally, in vitro tests have been performed with ethanolic extracts of some common macroalgae, as referred to in Table 2, Section 3, namely, H. tuna against M. phaseolina and R. solani, and Sargassum swartzii [71] and Melanothamnous afaghusainii $[72,74,75]$ against $R$. solani [109]. By using the disc diffusion method, no activity was noticed against these fungi [109], but in planta tests of the same macroalgae dry powder found that it inhibited the infection caused by these phytopathogens [71,74]. This could mean that either the antifungal compounds do not belong to the ethanolic fraction, which is unexpected, as the extracted lipophilic compounds are the ones reported to possess antifungal activity [66,132], or a direct antifungal activity is not the cause of infection suppression. The latter possibility seems plausible since dried macroalgae are also known to stimulate the growth of plants, as well as to contribute to a higher resistance against microorganisms, through the activation of intrinsic defence pathways [133-136]. This way, in the context of fighting fungal infections, one should include the potential of the compounds to act as elicitors, promoting the defence mechanisms of the plants, instead of direct antifungal activity against the phytopathogenic fungi, which, of course, triggers the need for different assessment strategies for algae extracts.

\section{Conclusions}

This review gives a résumé of all available information concerning the antifungal activity of macroalgae extracts against phytopathogenic fungi. A strong inhibitory capacity is ubiquitous among all different macroalgae groups, but the potential of brown algae is predominant. Fatty acids, phenolic compounds, terpenoids and their derivatives, and polysaccharides are some of the compounds of macroalgal origin responsible for inhibitory activity against the phytopathogenic fungi. Notwithstanding the number of available works 
in the area, more efforts are still needed to elucidate the specific compounds responsible for antifungal action, their chemical structures, and the mechanisms of action.

The enormous potential of a natural source of antifungal compounds is frequently seen as the future to combat the "silent fungal crisis" spread all over the world. The effectiveness of macroalgae-derived compounds is yet not fully disclosed and their potential introduction for agricultural purposes may reveal the onset of eco-friendly strategies, not only as antifungal agents, but also as elicitors of plant defence pathways.

Despite the natural sourcing, which gives increased societal acceptability, the optimization of assays that allow understanding of the influence of macroalgae compounds in non-target species is paramount to achieve the twofold goal of efficiency and low environmental impact. More studies conducted in field are necessary to ensure that the ability to control the development of fungal plant pathogens are not only present in in vitro tests but also in real conditions. The biotechnological use of marine resources for agriculture is still in its infancy, but the increased number of studies pinpointing their potential and success promises a future where the use of these natural compounds may further contribute to scaling up food supply and enhancing food security in order to meet the increasing demands for quality products from an ever-increasing population.

Supplementary Materials: The following are available online at https:/ / www.mdpi.com/article/10 $.3390 /$ jof7121006/s1, Table S1: Data available about the antifungal activity against phytopathogenic fungi from macroalgae using the disc/well diffusion technique; Table S2: Data available about the antifungal activity against phytopathogenic fungi from macroalgae using the modified diffusion technique; Table S3: Data available about the antifungal activity against phytopathogenic fungi from macroalgae using the poisoned food technique; Table S4: Data available about the antifungal activity against phytopathogenic fungi from macroalgae using the poisoned food technique (data expressed in mycelial growth); Table S5: Data available about the antifungal activity against phytopathogenic fungi from macroalgae by the evaluation of macroconidia germination; Table S6: Data available about the antifungal activity against phytopathogenic fungi from macroalgae using the broth microdilution assay; Table S7: Data available about the antifungal activity against phytopathogenic fungi from macroalgae by the evaluation of inhibition of mycelial growth (by spraying the fungi culture with macroalgae extract); Table S8: Data available about the antifungal activity against phytopathogenic fungi from macroalgae by the evaluation of fungal spore germination; Table S9: Data available about the antifungal activity against phytopathogenic fungi from macroalgae by the spore spreading method; Table S10: Data available about the antifungal activity against phytopathogenic fungi from macroalgae by the fungal germination in test tube; Table S11: Data available about the antifungal activity against phytopathogenic fungi from macroalgae tested in field studies; Table S12: Data available about the antifungal activity against phytopathogenic fungi from macroalgae tested in screenhouse studies.

Author Contributions: Conceptualization, T.F.L.V., C.F., R.F. and M.F.L.L.; writing一original draft preparation, T.F.L.V.; writing-review and editing, C.F., M.F.L.L. and P.V.; supervision, P.V. and M.F.L.L.; project administration, M.F.L.L.; funding acquisition, M.F.L.L. All authors have read and agreed to the published version of the manuscript.

Funding: This study was supported by the Fundação para a Ciência e a Tecnologia (FCT) to MARE (UID/MAR/04292/2020) through national funds and grant to Tânia Vicente (2020.06230.BD). The authors also acknowledge the support of project ORCHESTRA-add-value to ORCHards through thE full valoriSaTion of macRoalgAe (POCI-01-0247-FEDER-070155) co-funded by FEDER-Fundo Europeu de Desenvolvimento Regional da União Europeia, Portugal 2020, through COMPETE 2020-Programa Operacional Competitividade e Internacionalização and through FCT.

Institutional Review Board Statement: Not applicable.

Informed Consent Statement: Not applicable.

Data Availability Statement: Not applicable.

Conflicts of Interest: The authors declare no conflict of interest. 


\section{References}

1. Savary, S.; Ficke, A.; Aubertot, J.-N.; Hollier, C. Crop Losses Due to Diseases and Their Implications for Global Food Production Losses and Food Security. Food Secur. 2012, 4, 519-537. [CrossRef]

2. Rahman, S.F.S.A.; Singh, E.; Pieterse, C.M.J.; Schenk, P.M. Emerging Microbial Biocontrol Strategies for Plant Pathogens. Plant Sci. 2017, 267, 102-111. [CrossRef] [PubMed]

3. Tleuova, A.B.; Wielogorska, E.; Talluri, V.S.S.L.P.; Štěpánek, F.; Elliott, C.T.; Grigoriev, D.O. Recent Advances and Remaining Barriers to Producing Novel Formulations of Fungicides for Safe and Sustainable Agriculture. J. Control. Release 2020, 326, 468-481. [CrossRef] [PubMed]

4. Kannan, V.R.; Bastas, K.K.; Devi, R.S. Scientific and Economic Impact of Plant Pathogenic Bacteria. In Sustainable Approaches to Controlling Plant Pathogenic Bacteria; CRC Press: Boca Raton, FL, USA, 2015; pp. 369-392. [CrossRef]

5. Savary, S.; Willocquet, L.; Pethybridge, S.J.; Esker, P.; McRoberts, N.; Nelson, A. The Global Burden of Pathogens and Pests on Major Food Crops. Nat. Ecol. Evol. 2019, 3, 430-439. [CrossRef] [PubMed]

6. Strange, R.N.; Scott, P.R. Plant Disease: A Threat to Global Food Security. Annu. Rev. Phytopathol. 2005, 43, 83-116. [CrossRef]

7. Mokyr, J.; Gráda, C.Ó. What Do People Die of during Famines: The Great Irish Famine in Comparative Perspective. Eur. Rev. Econ. Hist. 2002, 6, 339-363. [CrossRef]

8. Fisher, M.C.; Henk, D.A.; Briggs, C.J.; Brownstein, J.S.; Madoff, L.C.; McCraw, S.L.; Gurr, S.J. Emerging Fungal Threats to Animal, Plant and Ecosystem Health. Nature 2012, 484, 186-194. [CrossRef]

9. Narayanasamy, P. Diagnosis of Bacterial Diseases of Plants. In Microbial Plant Pathogens-Detection and Disease Diagnosis: Bacterial and Phytoplasmal Pathogens; Springer: Dordrecht, The Netherlands, 2011; Volume 2, pp. 233-246. [CrossRef]

10. Shuping, D.S.S.; Eloff, J.N. The Use of Plants to Protect Plants and Food Against Fungal Pathogens: A Review. Afr. J. Tradit. Complement. Altern. Med. 2017, 14, 120-127. [CrossRef]

11. El Hussein, A.A.; Alhasan, R.E.M.; Abdelwahab, S.A.; El Siddig, M.A. Isolation and Identification of Streptomyces Rochei Strain Active against Phytopathogenic Fungi. Br. Microbiol. Res. J. 2014, 4, 1057-1068. [CrossRef]

12. Zabiák, A.; Károlyi, G.M.; Sándor, E. Investigation of Host-Specificity of Phytopathogenic Fungi Isolated from Woody Plants. Acta Agrar. Debreceniensis 2020, 1, 155-160. [CrossRef]

13. Kainz, K.; Bauer, M.A.; Madeo, F.; Carmona-Gutierrez, D. Fungal Infections in Humans: The Silent Crisis. Microb. Cell 2020, 7, 143-145. [CrossRef] [PubMed]

14. Coque, R.; Álvarez-Pérez, M.; Cobos, R.; González-García, S.; Ibáñez, A.M.; Galán, A.D.; Calvo-Peña, C. Advances in the Control of Phytopathogenic Fungi That Infect Crops through Their Root System. Adv. Appl. Microbiol. 2020, 111, 1-48. [CrossRef]

15. Cornelissen, B.J.C.; Melchers, L.S. Strategies for Control of Fungal Diseases with Transgenic Plants. Plant Physiol. 1993, 101, 709-712. [CrossRef]

16. De Waard, M.A.; Georgopoulos, S.G.; Hollomon, D.W.; Ishii, H.; Leroux, P.; Ragsdale, N.N.; Schwinn, F.J. Chemical Control of Plant Diseases: Problems and Prospects. Annu. Rev. Phytopathol. 1993, 31, 403-421. [CrossRef]

17. Hamed, S.M.; Abd El-Rhman, A.A.; Abdel-Raouf, N.; Ibraheem, I.B.M. Role of Marine Macroalgae in Plant Protection \& Improvement for Sustainable Agriculture Technology. Beni-Suef Univ. J. Basic Appl. Sci. 2018, 7, 104-110. [CrossRef]

18. Zhang, Z.; Chen, Y.; Li, B.; Chen, T.; Tian, S. Reactive Oxygen Species: A Generalist in Regulating Development and Pathogenicity of Phytopathogenic Fungi. Comput. Struct. Biotechnol. J. 2020, 18, 3344-3349. [CrossRef] [PubMed]

19. Badosa, E.; Ferre, R.; Planas, M.; Feliu, L.; Montesinos, E.; Cabrefiga, J.; Bardaj1, E.; Besalu, E. A Library of Linear Undecapeptides with Bactericidal Activity against Phytopathogenic Bacteria. Peptides 2007, 28, 2276-2285. [CrossRef]

20. Hahn, M. The Rising Threat of Fungicide Resistance in Plant Pathogenic Fungi: Botrytis as a Case Study. J. Chem. Biol. 2014, 7 , 133-141. [CrossRef]

21. Ma, Z.; Michailides, T.J. Advances in Understanding Molecular Mechanisms of Fungicide Resistance and Molecular Detection of Resistant Genotypes in Phytopathogenic Fungi. Crop Prot. 2005, 24, 853-863. [CrossRef]

22. Lorito, M.; Mach, R.L.; Sposato, P.; Strauss, J.; Peterbauer, C.K.; Kubicek, C.P. Mycoparasitic Interaction Relieves Binding of the Cre1 Carbon Catabolite Repressor Protein to Promoter Sequences of the ech42 (Endochitinase-Encoding) Gene in Trichoderma Harzianum. Proc. Natl. Acad. Sci. USA 1996, 93, 14868-14872. [CrossRef]

23. Lorito, M.; Harman, G.E.; Hayes, C.K.; Broadway, R.M.; Tronsmo, A.; Woo, S.L.; Di Pietro, A. Chinolytic Enzymes Produced by Trichoderma Harzianum: Antifungal Activity of Purified Endochitinase and Chitobiosidase. Mol. Plant Pathol. 1993, 83, 302-307.

24. Neeraja, C.; Anil, K.; Purushotham, P.; Suma, K.; Sarma, P.; Moerschbacher, B.M.; Podile, A.R. Biotechnological Approaches to Develop Bacterial Chitinases as a Bioshield against Fungal Diseases of Plants. Crit. Rev. Biotechnol. 2010, 30, 231-241. [CrossRef]

25. Chandra, H.; Kumari, P.; Bisht, R.; Prasad, R.; Yadav, S. Plant Growth Promoting Pseudomonas aeruginosa from Valeriana wallichii Displays Antagonistic Potential against Three Phytopathogenic Fungi. Mol. Biol. Rep. 2020, 47, 6015-6026. [CrossRef]

26. Lorito, M.; Peterbauer, C.; Hayes, C.K.; Harman, G.E. Synergistic Interaction between Fungal Cell Wall Degrading Enzymes and Different Antifungal Compounds Enhances Inhibition of Spore Germination. Microbiology 1994, 140, 623-629. [CrossRef] [PubMed]

27. Azcón-Aguilar, C.; Barea, J.M. Arbuscular Mycorrhizas and Biological Control of Soil-Borne Plant Pathogens-An Overview of the Mechanisms Involved. Mycorrhiza 1997, 6, 457-464. [CrossRef]

28. O'Brien, P.A. Biological Control of Plant Diseases. Australas. Plant Pathol. 2017, 46, 293-304. [CrossRef] 
29. Lorito, M.; Woo, S.L.; Fernandez, I.G.; Colucci, G.; Harman, G.E.; Pintor-Toro, J.A.; Filippone, E.; Muccifora, S.; Lawrence, C.B.; Zoina, A.; et al. Genes from Mycoparasitic Fungi as a Source for Improving Plant Resistance to Fungal Pathogens. Proc. Natl. Acad. Sci. USA 1998, 95, 7860-7865. [CrossRef]

30. Vidaver, A.K. Prospects for Control of Phytopathogenic Bacteria by Bacteriophages and Bacteriocins. Annu. Rev. Phytopathol. 1976, 14, 451-465. [CrossRef]

31. Alamri, S.; Hashem, M.; Mostafa, Y.S. in vitro and in vivo Biocontrol of Soil-Borne Phytopathogenic Fungi by Certain Bioagents and Their Possible Mode of Action. Biocontrol Sci. 2012, 17, 155-167. [CrossRef] [PubMed]

32. Samsatly, J.; Copley, T.R.; Jabaji, S.H. Antioxidant Genes of Plants and Fungal Pathogens Are Distinctly Regulated during Disease Development in Different Rhizoctonia solani Pathosystems. PLoS ONE 2018, 13, e0192682. [CrossRef]

33. DeGray, G.; Rajasekaran, K.; Smith, F.; Sanford, J.; Daniell, H. Expression of an Antimicrobial Peptide via the Chloroplast Genome to Control Phytopathogenic Bacteria and Fungi. Plant Physiol. 2001, 127, 852-862. [CrossRef]

34. Pathma, J.; Kennedy, R.K.; Bhushan, L.S.; Shankar, B.K.; Thakur, K. Microbial Biofertilizers and Biopesticides: Nature's Assets Fostering Sustainable Agriculture. In Recent Developments in Microbial Technologies; Springer: Singapore, $2021 ;$ pp. 39-69.

35. Kiuru, P.; D'Auria, M.V.; Muller, C.D.; Tammela, P.; Vuorela, H.; Yli-Kauhaluoma, J. Exploring Marine Resources for Bioactive Compounds. Planta Med. 2014, 80, 1234-1246. [CrossRef]

36. Nawaz, A.; Chaudhary, R.; Shah, Z.; Dufossé, L.; Fouillaud, M.; Mukhtar, H.; Haq, I.U. An Overview on Industrial and Medical Applications of Bio-Pigments Synthesized by Marine Bacteria. Microorganisms 2021, 9, 11. [CrossRef]

37. Milledge, J.J.; Nielsen, B.V.; Bailey, D. High-Value Products from Macroalgae: The Potential Uses of the Invasive Brown Seaweed, Sargassum Muticum. Rev. Environ. Sci. Biotechnol. 2016, 15, 67-88. [CrossRef]

38. Shannon, E.; Abu-Ghannam, N. Antibacterial Derivatives of Marine Algae: An Overview of Pharmacological Mechanisms and Applications. Mar. Drugs 2016, 14, 81. [CrossRef] [PubMed]

39. Rizzo, C.; Genovese, G.; Morabito, M.; Faggio, C.; Pagano, M.; Spanò, A.; Zammuto, V.; Minicante, S.A.; Manghisi, A.; Cigala, R.M.; et al. Potential Antibacterial Activity of Marine Macroalgae against Pathogens Relevant for Aquaculture and Human Health. J. Pure Appl. Microbiol. 2017, 11, 1695-1706. [CrossRef]

40. Besednova, N.N.; Andryukov, B.G.; Zaporozhets, T.S.; Kryzhanovsky, S.P.; Kuznetsova, T.A.; Fedyanina, L.N.; Makarenkova, I.D.; Zvyagintseva, T.N. Algae Polyphenolic Compounds and Modern Antibacterial Strategies: Current Achievements and Immediate Prospects. Biomedicines 2020, 8, 342. [CrossRef]

41. Khan, W.; Rayirath, U.P.; Subramanian, S.; Jithesh, M.N.; Rayorath, P.; Hodges, D.M.; Critchley, A.T.; Craigie, J.S.; Norrie, J.; Prithiviraj, B. Seaweed Extracts as Biostimulants of Plant Growth and Development. J. Plant Growth Regul. 2009, 28, 386-399. [CrossRef]

42. Brauer, V.S.; Rezende, C.P.; Pessoni, A.M.; De Paula, R.G.; Rangappa, K.S.; Nayaka, S.C.; Gupta, V.K.; Almeida, F. Antifungal Agents in Agriculture: Friends and Foes of Public Health. Biomolecules 2019, 9, 521. [CrossRef]

43. Dyakov, Y.T.; Zinovyeva, S.V. Plant Parasite Microorganisms. In Comprehensive and Molecular Phytopathology; Elsevier: Amsterdam, The Netherlands, 2007; pp. 19-47. [CrossRef]

44. Mendgen, K.; Hahn, M. Plant Infection and the Establishment of Fungal Biotrophy. Trends Plant Sci. 2002, 7, 352-356. [CrossRef]

45. Stuiver, M.H.; Custers, J.H.H.V. Engineering Disease Resistance in Plants. Nature 2001, 411, 865-868. [CrossRef]

46. Jayawardena, R.S.; Hyde, K.D.; McKenzie, E.H.C.; Jeewon, R.; Phillips, A.J.L.; Perera, R.H.; de Silva, N.I.; Maharachchikumburua, S.S.N.; Samarakoon, M.C.; Ekanayake, A.H.; et al. One Stop Shop III: Taxonomic Update with Molecular Phylogeny for Important Phytopathogenic Genera: 51-75 (2019); Springer: Dordrecht, The Netherlands, 2019; Volume 98. [CrossRef]

47. Marin-Felix, Y.; Groenewald, J.Z.; Cai, L.; Chen, Q.; Marincowitz, S.; Barnes, I.; Bensch, K.; Braun, U.; Camporesi, E.; Damm, U.; et al. Genera of Phytopathogenic Fungi: GOPHY 1. Stud. Mycol. 2017, 86, 99-216. [CrossRef] [PubMed]

48. Marin-Felix, Y.; Hernández-Restrepo, M.; Wingfield, M.J.; Akulov, A.; Carnegie, A.J.; Cheewangkoon, R.; Gramaje, D.; Groenewald, J.Z.; Guarnaccia, V.; Halleen, F.; et al. Genera of Phytopathogenic Fungi: GOPHY 2. Stud. Mycol. 2019, 92, 47-133. [CrossRef] [PubMed]

49. Marin-Felix, Y.; Hernández-Restrepo, M.; Iturrieta-González, I.; García, D.; Gené, J.; Groenewald, J.Z.; Cai, L.; Chen, Q.; Quaedvlieg, W.; Schumacher, R.K.; et al. Genera of Phytopathogenic Fungi: GOPHY 3. Stud. Mycol. 2019, 94, 1-124. [CrossRef]

50. Masuda, M.; Abe, T.; Sato, S.; Suzuki, T.; Suzuki, M. Diversity of Halogenated Secondary Metabolites in the Red Alga Laurencia Nipponica (Rhodomelaceae, Ceramiales). J. Phycol. 1997, 33, 196-208. [CrossRef]

51. Malini, M.; Ponnanikajamideen, M.; Malarkodi, C.; Rajeshkumar, S. Explore the Antimicrobial Potential from Organic Solvents Extract of Brown Seaweed (Sargassum longifolium) Alleviating to Pharmaceuticals. Int. J. Pharm. Res. 2014, 6, 28-35.

52. Khan, S.A.; Abid, M.; Hussain, F. Antifungal Activity of Aqueous and Methanolic Extracts of Some Seaweeds against Common Soil-Borne Plant Pathogenic Fungi. Pak. J. Bot. 2017, 49, 1211-1216.

53. Pohl, C.H.; Kock, J.L.F.; Thibane, V.S. Antifungal Free Fatty Acids: A Review. Sci. Against Microb. Pathog. Curr. Res. Technol. Adv. 2011, 3, 61-71.

54. Avis, T.J.; Bélanger, R.R. Specificity and Mode of Action of the Antifungal Fatty Acid Cis-9-Heptadecenoic Acid Produced by Pseudozyma flocculosa. Appl. Environ. Microbiol. 2001, 67, 956-960. [CrossRef]

55. Desbois, A.P.; Smith, V.J. Antibacterial Free Fatty Acids: Activities, Mechanisms of Action and Biotechnological Potential. Appl. Microbiol. Biotechnol. 2010, 85, 1629-1642. [CrossRef] 
56. Mohamed, S.S.; Saber, A.A. Antifungal Potential of the Bioactive Constituents in Extracts of the Mostly Untapped Brown Seaweed Hormophysa cuneiformis from The Egyptian Coastal Waters. Egypt. J. Bot. 2019, 59, 695-708. [CrossRef]

57. Tyśkiewicz, K.; Tyśkiewicz, R.; Konkol, M.; Rój, E.; Jaroszuk-Ściseł, J.; Skalicka-Woźniak, K. Antifungal Properties of Fucus vesiculosus L. Supercritical Fluid Extract Against Fusarium culmorum and Fusarium oxysporum. Molecules 2019, 24, 3518. [CrossRef] [PubMed]

58. Vehapi, M.; Koçer, A.T.; Yılmaz, A.; Özçimen, D. Investigation of the Antifungal Effects of Algal Extracts on Apple-infecting Fungi. Arch. Microbiol. 2020, 202, 455-471. [CrossRef]

59. Ali, N.; Ramkissoon, A.; Ramsubhag, A.; Jayaraj, J. Ascophyllum Extract Application Causes Reduction of Disease Levels in Field Tomatoes Grown in a Tropical Environment. Crop Prot. 2016, 83, 67-75. [CrossRef]

60. D'Mello, J.P.F.; Macdonald, A.M.C.; Postel, D.; Dijksma, W.T.P.; Dujardin, A.; Placinta, C.M. Pesticide Use and Mycotoxin Production in Fusarium and Aspergillus Phytopathogens. Eur. J. Plant Pathol. 1998, 104, 741-751. [CrossRef]

61. Windham, G.L.; Williams, W.P.; Davis, F.M. Effects of the Southwestern Corn Borer on Aspergillus flavus Kernel Infection and Aflatoxin Accumulation in Maize Hybrids. Plant Dis. 1999, 83, 535-540. [CrossRef]

62. Kelley, R.Y.; Williams, W.P.; Mylroie, J.E.; Boykin, D.L.; Harper, J.W.; Windham, G.L.; Ankala, A.; Shan, X. Identification of Maize Genes Associated with Host Plant Resistance or Susceptibility to Aspergillus flavus Infection and Aflatoxin Accumulation. PLoS ONE 2012, 7, 12. [CrossRef]

63. Belattmania, Z.; Reani, A.; Barakate, M.; Zrid, R.; Elatouani, S.; Hassouani, M.; Eddaoui, A.; Bentiss, F.; Sabour, B. Antimicrobial, Antioxidant and Alginate Potentials of Dictyopteris polypodioides (Dictyotales, Phaeophyceae) from the Moroccan Atlantic Coast. Der Pharma Chem. 2016, 8, 216-226.

64. Dean, R.; Van Kan, J.A.L.; Pretorius, Z.A.; Hammond-Kosack, K.E.; Di Pietro, A.; Spanu, P.D.; Rudd, J.J.; Dickman, M.; Kahmann, R.; Ellis, J.; et al. The Top 10 Fungal Pathogens in Molecular Plant Pathology. Mol. Plant Pathol. 2012, 13, 414-430. [CrossRef]

65. Moreau, J.; Pesando, D.; Bernard, P.; Caram, B.; Pionnat, J.C. Seasonal Variations in the Production of Antifungal Substances by Some Dictyotales (Brown Algae) from the French Mediterranean Coast. Hydrobiologia 1988, 162, 157-162. [CrossRef]

66. Ambika, S.; Sujatha, K. Antifungal Activity of Aqueous and Ethanol Extracts of Seaweeds against Sugarcane Red Rot Pathogen (Colletotrichum falcatum). Sci. Res. Essays 2015, 10, 232-235. [CrossRef]

67. Machado, L.P.; Matsumoto, S.T.; Jamal, C.M.; Silva, M.B.; da Cruz Centeno, D.; Neto, P.C.; Carvalho, L.R.; Yokoya, N.S. Chemical Analysis and Toxicity of Seaweed Extracts with Inhibitory Activity against Tropical Fruit Anthracnose Fungi. J. Sci. Food Agric. 2013, 94, 1739-1744. [CrossRef]

68. Machado, L.P.; Matsumoto, S.T.; Cuzzuol, G.R.F.; Oliveira, L.F.G., Jr. Influence of Laboratory Cultivation on Species of Rhodophyta Physiological Evaluations and Antifungal Activity against Phytopathogens. Rev. Ciênc. Agron. 2014, 45, 52-61. [CrossRef]

69. Mani, S.D.; Nagarathnam, R. Sulfated Polysaccharide from Kappaphycus Alvarezii (Doty) Doty Ex P.C. Silva Primes Defense Responses against Anthracnose Disease of Capsicum annuum Linn. Algal Res. 2018, 32, 121-130. [CrossRef]

70. Ishimoto, H.; Fukushi, Y.; Yoshida, T.; Tahara, S. Rhizopus and Fusarium Are Selected as Dominant Fungal Genera in Rhizospheres of Brassicaceae. J. Chem. Ecol. 2000, 26, 2387-2399. [CrossRef]

71. Ehteshamul-Haque, S.; Baloch, G.N.; Sultana, V.; Ara, J.; Tariq, R.M.; Athar, M. Impact of Seaweeds on Fluorescent Pseudomonas and Their Role in Suppressing the Root Diseases of Soybean and Pepper. J. Appl. Bot. Food Qual. 2013, 86, 126-132. [CrossRef]

72. Baloch, G.N.; Tariq, S.; Ehteshamul-Haque, S.; Athar, M.; Sultana, V.; Ara, J. Management of Root Diseases of Eggplant and Watermelon with the Application of Asafoetida and Seaweeds. J. Appl. Bot. Food Qual. 2013, 86, 138-142. [CrossRef]

73. Sultana, V.; Ehteshamul-Haque, S.; Ara, J.; Athar, M. Effect of Brown Seaweeds and Pesticides on Root Rotting Fungi and Root-Knot Nematode Infecting Tomato Roots. J. Appl. Bot. Food Qual. 2009, 83, 50-53.

74. Sultana, V.; Tariq, S.; Hira, K.; Tariq, A.; Ara, J.; Tariq, R.M.; Ehteshamul-Haque, S. Seaweed Bio-Fertilizer for the Management of Root Rotting Fungi and Root Knot Nematodes Affecting Cotton Crop. Pak. J. Bot. 2018, 50, 2409-2412.

75. Sultana, V.; Baloch, G.N.; Ara, J.; Ehteshamul-Haque, S.; Tariq, R.M.; Athar, M. Seaweeds as Alternative to Chemical Pesticides for the Management of Root Diseases of Sunflower and Tomato. J. Appl. Bot. Food Qual. 2011, 84, 162-168.

76. Vitoratos, A.; Bilalis, D.; Karkanis, A.; Efthimiadou, A. Antifungal Activity of Plant Essential Oils Against Botrytis cinerea, Penicillium italicum and Penicillium digitatum. Not. Bot. Horti Agrobot. Cluj-Napoca 2013, 41, 86-92. [CrossRef]

77. Neri, F.; Mari, M.; Brigati, S. Control of Penicillium expansum by Plant Volatile Compounds. Plant Pathol. 2006, 55, 100-105. [CrossRef]

78. Ivanov, S.; Miteva, L.; Alexieva, V.; Karjin, H.; Karanov, E. Alterations in Some Oxidative Parameters in Susceptible and Resistant Wheat Plants Infected with Puccinia recondita f. Sp. tritici. J. Plant Physiol. 2005, 162, 275-279. [CrossRef] [PubMed]

79. Graff, K.H.; Raj, T.S. Effect of Sargassum tenerrimum on Controlling Sheath Blight of Rice Caused by Rhizoctonia solani Kuhn. Plant Arch. 2019, 19, 1132-1135.

80. Cordovez, V.; Mommer, L.; Moisan, K.; Lucas-Barbosa, D.; Pierik, R.; Mumm, R.; Carrion, V.J.; Raaijmakers, J.M. Plant Phenotypic and Transcriptional Changes Induced by Volatiles from the Fungal Root Pathogen Rhizoctonia solani. Front. Plant Sci. 2017, 8, 1262. [CrossRef] [PubMed]

81. Jiménez, E.; Dorta, F.; Medina, C.; Ramírez, A.; Ramírez, I.; Peña-Cortés, H. Anti-Phytopathogenic Activities of Macro-Algae Extracts. Mar. Drugs 2011, 9, 739-756. [CrossRef] 
82. Robles-Centeno, P.O.; Ballantine, D.L.; Gerwick, W.H. Dynamics of Antibacterial Activity in Three Species of Caribbean Marine Algae as a Function of Habitat and Life History. Hydrobiologia 1996, 326-327, 457-462. [CrossRef]

83. Ballantine, D.L.; Gerwick, W.H.; Velez, S.M.; Alexander, E.; Guevara, P. Antibiotic Activity of Lipid-Soluble Extracts from Caribbean Marine Algae. Hydrobiologia 1987, 151-152, 463-469. [CrossRef]

84. Khaleafa, A.F.; Kharboush, M.A.M.; Metwalli, A.; Mohsen, A.F.; Serwi, A. Antibiotic (Fungicidal) Action from Extracts of Some Seaweeds. Bot. Mar. 1975, XVIII, 163-165. [CrossRef]

85. Kumar, K.A.; Rengasamy, R. Evaluation of Antibacterial Potential of Seaweeds Occurring along the Coast of Tamil Nadu, India against the Plant Pathogenic Bacterium Xanthomonas oryzae Pv. oryzae (Ishiyama) Dye. Bot. Mar. 2000, 43, 409-415.

86. Rao, P.P.S.; Rao, P.S.; Karmarkar, S.M. Antibacterial Substances from Brown Algae II. Efficiency of Solvents in the Evaluation of Antibacterial Substances from Sargassum Johnstonü Setchell et Gardner. Bot. Mar. 1986, XXIX, 503-507.

87. Lakhdar, F.; Boujaber, N.; Oumaskour, K.; Assobhei, O.; Etahiri, S. Inhibitive Activity of 17 Marine Algae from the Coast of El Jadida-Morocco against Erwinia chrysanthemi. Int. J. Pharm. Pharm. Sci. 2015, 7, 376-380.

88. Kamenarska, Z.; Serkedjieva, J.; Najdenski, H.; Stefanov, K.; Tsvetkova, I.; Dimitrova-Konaklieva, S.; Popov, S. Antibacterial, Antiviral, and Cytotoxic Activities of Some Red and Brown Seaweeds from the Black Sea. Bot. Mar. 2009, 52, 80-86. [CrossRef]

89. Caccamese, S.; Azzolina, R.; Furnari, G.; Cormaci, M.; Grasso, S. Antimicrobial and Antiviral Activities of Some Marine Algae from Eastern Sicily. Bot. Mar. 1981, XXIV, 365-367. [CrossRef]

90. Kumar, K.A.; Rengasamy, R. Antibacterial Activities of Seaweed Extracts/Fractions Obtained through a TLC Profile against the Phytopathogenic Bacterium Xanthomonas oryzae Pv. oryzae. Bot. Mar. 2000, 43, 417-421.

91. Rao, P.S.; Parekh, K.S. Antibacterial Activity of Indian Seaweed Extracts. Bot. Mar. 1981, XXIV, 577-582. [CrossRef]

92. Fenical, W.; Sims, J.J. Zonarol and Isozonarol, Fungitoxic Hydroquinones from the Brown Seaweed Dictyopteris zonarioides. J. Org. Chem. 1973, 38, 2383-2386. [CrossRef] [PubMed]

93. Esserti, S.; Smaili, A.; Rifai, L.A.; Koussa, T.; Makroum, K.; Belfaiza, M.; Kabil, E.M.; Faize, L.; Burgos, L.; Alburquerque, N.; et al. Protective Effect of Three Brown Seaweed Extracts against Fungal and Bacterial Diseases of Tomato. J. Appl. Phycol. 2017, 29, 1081-1093. [CrossRef]

94. Gómez-Hernández, M.; Rodríguez-García, C.M.; Peraza-Echeverría, L.; Peraza-Sánchez, S.R.; Torres-Tapia, L.W.; Pérez-Brito, D.; Vargas-Coronado, R.F.; Cauich-Rodríguez, J.V. In Vitro Antifungal Activity Screening of Beach-Cast Seaweeds Collected in Yucatan, Mexico. J. Appl. Phycol. 2021, 33, 1229-1237. [CrossRef]

95. Zhang, Y.; Han, J.; Mu, J.; Feng, Y.; Gu, X.; Ji, Y. Bioactivity and Constituents of Several Common Seaweeds. Chin. Sci. Bull. 2013, 58, 2282-2289. [CrossRef]

96. Rizvi, M.A.; Shameel, M. Pharmaceutical Biology of Seaweeds from the Karachi Coast of Pakistan Pharmaceutical. Pharm. Biol. 2005, 43, 97-107. [CrossRef]

97. Ali, N.; Farrell, A.; Ramsubhag, A.; Jayaraman, J. The Effect of Ascophyllum nodosum Extract on the Growth, Yield and Fruit Quality of Tomato Grown under Tropical Conditions. J. Appl. Phycol. 2016, 28, 1353-1362. [CrossRef]

98. Xiao, C.L.; Mackenzie, S.J.; Legard, D.E. Genetic and Pathogenic Analyses of Colletotrichum gloeosporioides Isolates from Strawberry and Noncultivated Hosts. Phytopathology 2004, 94, 446-453. [CrossRef] [PubMed]

99. Viswanathan, R.; Samiyappan, R. Induced Systemic Resistance by Fluorescent Pseudomonads against Red Rot Disease of Sugarcane Caused by Colletotrichum falcatum. Crop Prot. 2002, 21, 1-10. [CrossRef]

100. Qureshi, M.A.; Afghan, S. Sugarcane Cultivation in Pakistan; Pakistan Society of Sugar Technologists: Sindh, Pakistan, 2005.

101. Paul, V.J.; Hay, M.E.; Duffy, J.E.; Fenical, W.; Gustafson, K. Chemical Defense in the Seaweed Ochtodes secundiramea (Montagne) Howe (Rhodophyta): Effects of Its Monoterpenoid Components upon Diverse Coral-Reef Herbivores. J. Exp. Mar. Biol. Ecol. 1987, 114, 249-260. [CrossRef]

102. Peres, J.C.F.; de Carvalho, L.R.; Gonçalez, E.; Berian, L.O.S.; Felicio, J.D. Evaluation of Antifungal Activity of Seaweed Extracts. Ciênc. Agrotecnol. 2012, 36, 294-299. [CrossRef]

103. Yoshie-Stark, Y.; Hsieh, Y.-P.; Takeshi, S. Distribution of Flavonoids and Related Compounds from Seaweeds in Japan. J. Tokyo Univ. Fish. 2003, 89, 1-6.

104. Walters, D.; Raynor, L.; Mitchell, A.; Walker, R.; Walker, K. Antifungal Activities of Four Fatty Acids against Plant Pathogenic Fungi. Mycopathologia 2004, 157, 87-90. [CrossRef]

105. Ambika, S.; Sujatha, K. Comparative Studies on Brown, Red and Green Alga Seaweed Extracts for Their Antifungal Activity against Fusarium oxysporum f.Sp. udum in Pigeon Pea Var. CO (Rg)7 (Cajanus cajan (L.) Mills.). J. Biopestic. 2014, 7, 167-176.

106. Bennamara, A.; Abourriche, A.; Berrada, M.; Charrouf, M.; Chaib, N.; Boudouma, M.; Garneau, F.X. Methoxybifurcarenone: An Antifungal and Antibacterial Meroditerpenoid from the Brown Alga Cystoseira tamariscifolia. Phytochemistry 1999, 52, 37-40. [CrossRef]

107. Vahdani, M.; Faridi, P.; Zarshenas, M.M.; Javadpour, S.; Abolhassanzadeh, Z.; Moradi, N.; Bakzadeh, Z.; Karmostaji, A.; Mohagheghzadeh, A.; Ghasemi, Y. Major Compounds and Antimicrobial Activity of Essential Oils from Five Iranian Endemic Medicinal Plants. Pharmacogn. J. 2011, 3, 48-53. [CrossRef]

108. Altieri, C.; Bevilacqua, A.; Cardillo, D.; Sinigaglia, M. Antifungal Activity of Fatty Acids and Their Monoglycerides against Fusarium Spp. in a Laboratory Medium. Int. J. Food Sci. Technol. 2009, 44, 242-245. [CrossRef] 
109. Ambreen, A.; Khan, H.; Tariq, A.; Ruqqia, A.; Sultana, V.; Ara, J. Evaluation of Biochemical Component and Antimicrobial Activity of Some Seaweeeds Occurring at Karachi Coast. Pak. J. Bot. 2012, 44, 1799-1803.

110. Islam, M.S.; Haque, M.S.; Islam, M.M.; Emdad, E.M.; Halim, A.; Hossen, Q.M.M.; Hossain, M.Z.; Ahmed, B.; Rahim, S.; Rahman, M.S.; et al. Tools to Kill: Genome of One of the Most Destructive Plant Pathogenic Fungi Macrophomina phaseolina. BMC Genom. 2012, 13, 1-16. [CrossRef] [PubMed]

111. Shafique, H.A.; Sultana, V.; Ehteshamul-Haque, S.; Athar, M. Management of Soil-Borne Diseases of Organic Vegetables. J. Plant Prot. Res. 2016, 56, 221-230. [CrossRef]

112. Agarwal, P.; Patel, K.; Das, A.K.; Ghosh, A. Insights into the Role of Seaweed Kappaphycus alvarezii Sap towards Phytohormone Signalling and Regulating Defence Responsive Genes in Lycopersicon esculentum. Environ. Boil. Fishes 2016, 28, $2529-2537$. [CrossRef]

113. Nelson, W.R.; Van Staden, J. Aminocyclopropane-1-Carboxylic Acid in Seaweed Concentrate. Bot. Mar. 1985, XXVIII, 415-417. [CrossRef]

114. Kajiwara, T.; Matsui, K.; Akakabe, Y.; Murakawa, T.; Arai, C. Antimicrobial Browning-Inhibitory Effect of Flavor Compounds in Seaweeds. J. Appl. Bot. Food Qual. 2006, 18, 413-422. [CrossRef]

115. Kubo, I.; Himejima, M.; Tsujimoto, K.; Muroi, H.; Ichikawa, N. Antibacterial Activity of Crinitol and Its Potentiation. J. Nat. Prod. 1992, 55, 780-785. [CrossRef]

116. National Center for Biotechnology Information. PubChem Compound Summary for CID 6441081, Crinitol. Available online: https:/ / pubchem.ncbi.nlm.nih.gov/ compound/Crinitol (accessed on 2 October 2021).

117. Silva, P.; Fernandes, C.; Barros, L.; Ferreira, I.C.F.R.; Pereira, L.; Gonçalves, T. The Antifungal Activity of Extracts of Osmundea pinnatifida, an Edible Seaweed, Indicates Its Usage as a Safe Environmental Fungicide or as a Food Additive Preventing PostHarvest Fungal Food Contamination. Food Funct. 2018, 9, 6187-6195. [CrossRef]

118. Manilal, A.; Sujith, S.; Kiran, G.S.; Selvin, J.; Shakir, C.; Gandhimathi, R.; Lipton, A.P. Antimicrobial Potential and Seasonality of Red Algae Collected from the Southwest Coast of India Tested against Shrimp, Human and Phytopathogens. Ann. Microbiol. 2009, 59, 207-219. [CrossRef]

119. El-sheekh, M.M.; Mousa, A.S.H.; Farghl, A.A.M. Biological Control of Fusarium Wilt Disease of Tomato Plants Using Seaweed Extracts. Arab. J. Sci. Eng. 2020, 45, 4557-4570. [CrossRef]

120. Ara, J.; Sultana, V.; Qasim, R.; Ehteshamul-Haque, S.; Ahmad, V.U. Biological Activity of Spatoglossum asperum: A Brown Alga. Phyther. Res. 2005, 19, 618-623. [CrossRef]

121. Sultana, V.; Baloch, G.N.; Ambreen; Ara, J.; Tariq, M.R.; Ehteshamul-Haque, S. Comparative Efficacy of a Red Alga Solieria robusta, Chemical Fertilizers and Pesticides in Managing the Root Diseases and Growth of Soybean. Pak. J. Bot. 2011, 43, 1-6.

122. Aziz, S.D.A.; Jafarah, N.F.; Sabri, S.; Wahab, M.A.A.; Yusof, Z.N.B. Antifungal Activities against Oil Palm Pathogen Ganoderma boninense from Seaweed Sources. Asia-Pacific J. Mol. Biol. Biotechnol. 2019, 27, 75-83. [CrossRef]

123. Zouaoui, B.; Ghalem, B.R. The Phenolic Contents and Antimicrobial Activities of Some Marine Algae from the Mediterranean Sea (Algeria). Russ. J. Mar. Biol. 2017, 43, 491-495. [CrossRef]

124. Ghannoum, M.A.; Rice, L.B. Antifungal Agents: Mode of Action, Mechanisms of Resistance, and Correlation of These Mechanisms with Bacterial Resistance. Clin. Microbiol. Rev. 1999, 12, 501-517. [CrossRef] [PubMed]

125. Martins, V.D.P.; Dinamarco, T.M.; Curti, C.; Uyemura, S.A. Classical and Alternative Components of the Mitochondrial Respiratory Chain in Pathogenic Fungi as Potential Therapeutic Targets. J. Bioenerg. Biomembr. 2011, 43, 81-88. [CrossRef] [PubMed]

126. Lopes, G.; Pinto, E.; Andrade, P.B.; Valentão, P. Antifungal Activity of Phlorotannins against Dermatophytes and Yeasts: Approaches to the Mechanism of Action and Influence on Candida albicans Virulence Factor. PLoS ONE 2013, 8, e72203. [CrossRef] [PubMed]

127. Avis, T.J. Antifungal Compounds That Target Fungal Membranes: Applications in Plant Disease Control. Can. J. Plant Pathol. 2007, 29, 323-329. [CrossRef]

128. Hajlaou, M.R.; Traquair, J.A.; Jarvis, W.R.; Bélanger, R.R. Antifungal Activity of Extracellular Metabolites Produced by Sporothrix flocculosa. Biocontrol Sci. Technol. 1994, 4, 229-237. [CrossRef]

129. Ohvo-Rekilä, H.; Ramstedt, B.; Leppimäki, P.; Slotte, J.P. Cholesterol Interactions with Phospholipids in Membranes. Prog. Lipid Res. 2002, 41, 66-97. [CrossRef]

130. Thibane, V.S.; Kock, J.L.F.; Ells, R.; van Wyk, P.W.J.; Pohl, C.H. Effect of Marine Polyunsaturated Fatty Acids on Biofilm Formation of Candida albicans and Candida dubliniensis. Mar. Drugs 2010, 8, 2597-2604. [CrossRef]

131. Stengel, D.B.; Connan, S. Natural Products from Marine Algae: Methods and Protocols. In Natural Products From Marine Algae; Humana Press: New York, NY, USA, 2015; Volume 1308, pp. 1-439. [CrossRef]

132. Abd El-Baky, H.H.; El Baz, F.K.; El-Baroty, G.S. Evaluation of Marine Alga Ulva lactuca L. as a Source of Natural Preservative Ingredient. Electron. J. Environ. Agric. Food Chem. 2008, 7, 3353-3367.

133. Subramanian, S.; Sangha, J.S.; Gray, B.A.; Singh, R.P.; Hiltz, D.; Critchley, A.T.; Prithiviraj, B. Extracts of the Marine Brown Macroalga, Ascophyllum nodosum, Induce Jasmonic Acid Dependent Systemic Resistance in Arabidopsis thaliana against Pseudomonas syringae Pv. Tomato DC3000 and Sclerotinia sclerotiorum. Eur. J. Plant Pathol. 2011, 131, 237-248. [CrossRef] 
134. Jaulneau, V.; Lafitte, C.; Corio-Costet, M.-F.; Stadnik, M.J.; Salamagne, S.; Briand, X.; Esquerré-Tugayé, M.-T.; Dumas, B. An Ulva armoricana Extract Protects Plants against Three Powdery Mildew Pathogens. Eur. J. Plant Pathol. 2011, 131, 393-401. [CrossRef]

135. Vera, J.; Castro, J.; Gonzalez, A.; Moenne, A. Seaweed Polysaccharides and Derived Oligosaccharides Stimulate Defense Responses and Protection against Pathogens in Plants. Mar. Drugs 2011, 9, 2514-2525. [CrossRef]

136. Paulert, R.; Ebbinghaus, D.; Urlass, C.; Moerschbacher, B.M. Priming of the Oxidative Burst in Rice and Wheat Cell Cultures by Ulvan, a Polysaccharide from Green Macroalgae, and Enhanced Resistance against Powdery Mildew in Wheat and Barley Plants. Plant Pathol. 2010, 59, 634-642. [CrossRef] 